\title{
ZONAS GOSTERAS
}

\section{ESTUDIO OCEANOGRAFICO Y DE CALIDAD DE LAS AGUAS Y SEDIMENTOS DEL ORIENTE VENEZOLANO.}

\section{GOSTAS DE GUANTA Y PERTIGALETE}

\section{INFORME TECNICO}

Preparado por:

Dr. William Senior

Dr. Julián Castañeda

Gregorio Martínez

Cumaná, Abril de 1999. 


\section{TABLA DE CONTENIDO}

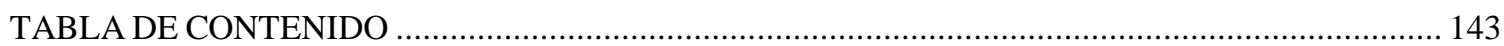

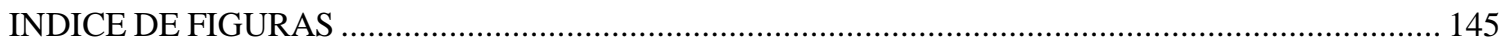

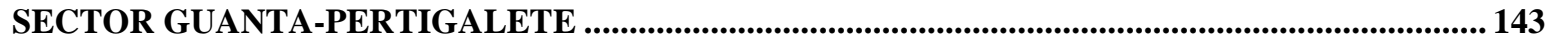

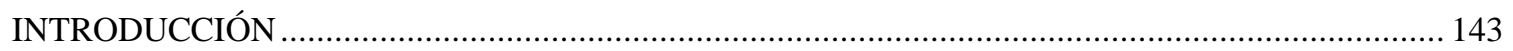

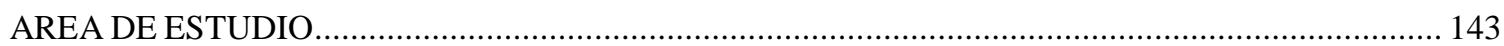

ADQUISICIÓN Y UBICACIÓN DE LOS PUNTOS DE MUESTREOS. .................................................. 143

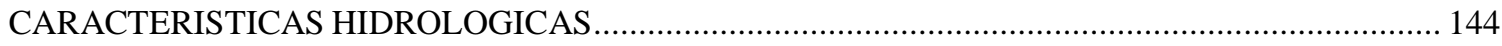

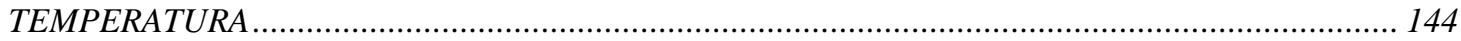

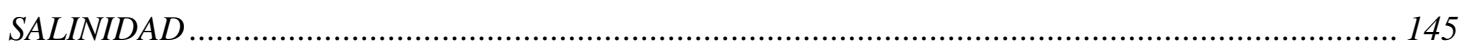

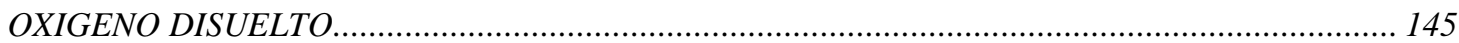

pH

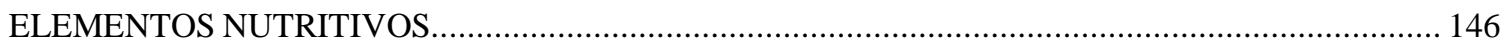

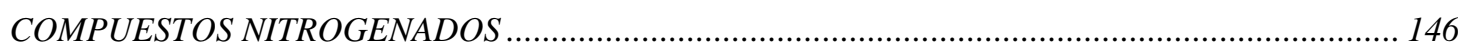

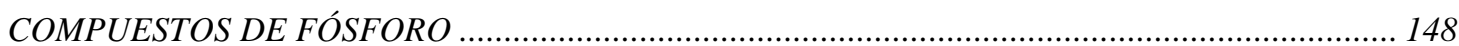

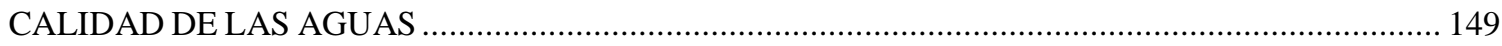

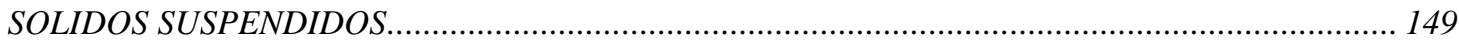

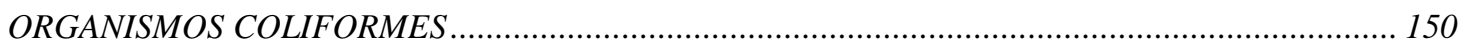

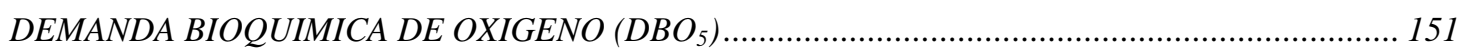

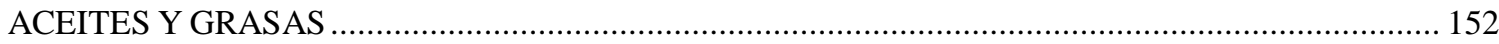

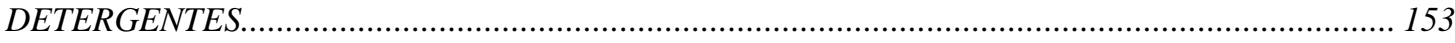

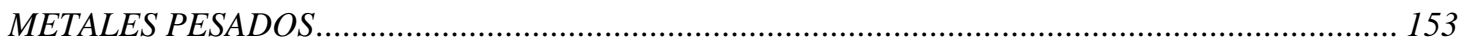

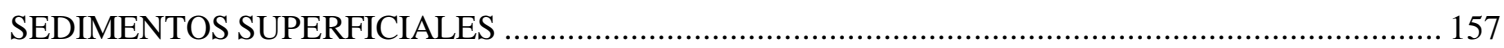

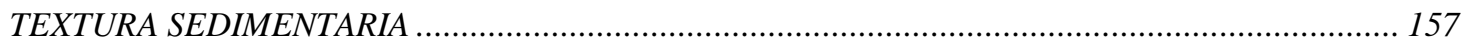

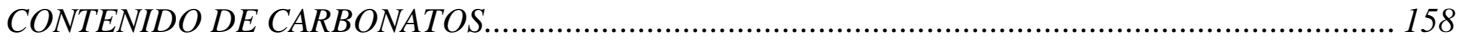

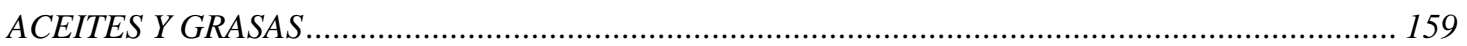

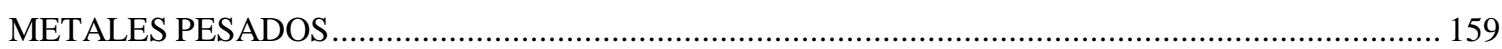

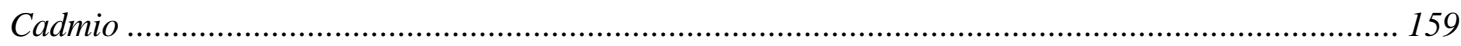

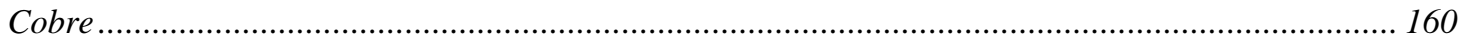

Cromo

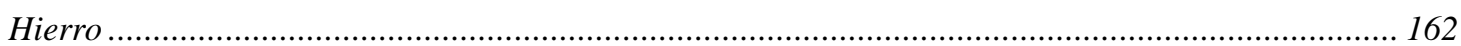

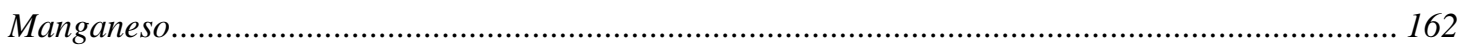

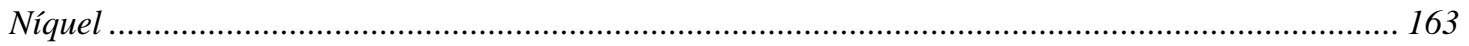

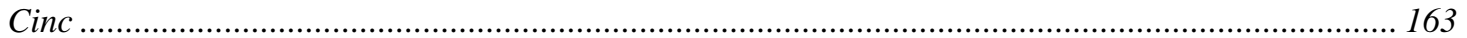




\section{INDICE DE FIGURAS}

Figura 1.- Localización espacial de las estaciones de muestreo. Los círculos azules llenos representan las estaciones de aguas, los círculos azules con borde rojo representas las estaciones simultáneas de agua y sedimento. 144

Figura 2.- Distribución espacial de la temperatura superficial $\left({ }^{\circ} \mathrm{C}\right)$ en el sector Guanta Pertigalete., durante marzo de 1999. 145

Figura 3.- Distribución espacial de la salinidad superficial (sin unidades) en el sector Guanta Pertigalete, durante Marzo de 1999. 145

Figura 4.- Distribución espacial del oxígeno disuelto (mg/l) en el sector Guanta Pertigalete, 11 Marzo de 1999 146

Figura 5.- Distribución espacial del pH superficial (mg/l) en el sector Guanta Pertigalete, 11 Marzo de 1999 146

Figura 6.- Distribución espacial del Amonio superficial ( $\mu \mathrm{mol} / /)$ en el sector Guanta Pertigalete, 11 Marzo de 1999 147

Figura 7- Distribución espacial del Nitrito + Nitrato superficial $(\mu \mathrm{mol} / \mathrm{l})$ en el sector Guanta Pertigalete, 11 Marzo de 1999 148

Figura 8.- Distribución espacial del Nitrógeno Total superficial ( $\mu \mathrm{mol} / /)$ en el sector Guanta Pertigalete, 11 Marzo de 1999 148

Figura 9- Distribución espacial del fosfato superficial ( $\mu \mathrm{mol} / \mathrm{l})$ en el sector Guanta Pertigalete, 11 Marzo de 1999 149

Figura 10.- Distribución espacial del fósforo total superficial ( $\mu \mathrm{mol} / /)$ en el sector Guanta Pertigalete, 11 Marzo de 1999 
Figura 11- Distribución espacial de los sólidos suspendidos (mg/l) en las aguas superficiales en el sector Guanta Pertigalete, 11 Marzo de 1999

Figura 12.- Distribución espacial de los coliformes fecales (NMP/100 ml) en las aguas superficiales del sector Guanta Pertigalete, 11 Marzo de 1999. 150

Figura 13.- Distribución espacial de los coliformes fecales (NMP/100 ml) en las aguas superficiales del sector Guanta Pertigalete, 11 Marzo de 1999. 151

Figura 14- Distribución espacial de la demanda biológica de oxígeno ( $\mathrm{mg} / \mathrm{l})$ en las aguas superficiales del sector Guanta-Pertigalete, 11 Marzo de 1999 152

Figura 15- Distribución espacial de los aceites y grasas (mg/l) en las aguas superficiales del sector Guanta-Pertigalete, 11 Marzo de 1999. 152

Figura 16- Distribución espacial de los detergentes $(\mathrm{mg} / \mathrm{ll}$ ) en las aguas superficiales del sector Guanta-Pertigalete, 11 Marzo de 1999. 153

Figura 17- Distribución espacial del Cinc $(\mu \mathrm{g} / \mathrm{l})$ en las aguas superficiales del sector GuantaPertigalete, 11 Marzo de 1999. 154

Figura 18.- Distribución espacial del cobre $(\mu \mathrm{g} / /)$ en las aguas superficiales del sector GuantaPertigalete, 11 Marzo de 1999. 154

Figura 19.- Distribución espacial del plomo $(\mu \mathrm{g} / \mathrm{l})$ en las aguas superficiales del sector GuantaPertigalete, 11 Marzo de 1999. 155

Figura 20.- Distribución espacial del cromo ( $\mu \mathrm{g} / \mathrm{l})$ en las aguas superficiales del sector GuantaPertigalete, 11 Marzo de 1999. 156

Figura 21.- Distribución espacial del hierro $(\mu \mathrm{g} / \mathrm{l})$ en las aguas superficiales del sector GuantaPertigalete, 11 Marzo de 1999. 156

Figura 22- Distribución espacial del manganeso ( $\mu \mathrm{g} / \mathrm{l})$ en las aguas superficiales del sector GuantaPertigalete, 11 Marzo de 1999. 156 
Figura 23.- Distribución espacial de los porcentajes de textura del sedimento: tipo arena sector GuantaPertigalete, 11 Marzo de 1999. 157

Figura 24.- Distribución espacial de los porcentajes de textura del sedimento: tipo arcilla sector GuantaPertigalete, 11 Marzo de 1999. 157

Figura 25.- Distribución espacial de los porcentajes de textura del sedimento: tipo limo sector GuantaPertigalete, 11 Marzo de 1999. 158

Figura 26- Distribución espacial de los porcentajes de textura del sedimento: tipo carbonato cálcico sector Guanta-Pertigalete, 11 Marzo de 1999 158

Figura 27- Distribución espacial de las concentraciones de aceites y grasas $(\mathrm{mg} / \mathrm{g})$ encontradas en los sedimentos superficiales del sector Guanta-Pertigalete, 11 Marzo de 1999. 159

Figura 28.- Distribución espacial de las concentraciones de cadmio $(\mu \mathrm{g} / \mathrm{g})$ encontradas en los sedimentos superficiales del sector Guanta-Pertigalete, 11 Marzo de 1999. 160

Figura 29- Distribución espacial de las concentraciones de cobre $(\mu \mathrm{g} / \mathrm{g})$ encontradas en los sedimentos superficiales del sector Guanta-Pertigalete, 11 Marzo de 1999. 161

Figura 30.- Distribución espacial de las concentraciones de cromo $(\mu \mathrm{g} / \mathrm{g})$ encontradas en los sedimentos superficiales del sector Guanta-Pertigalete, 11 Marzo de 1999. 161

Figura 31.- Distribución espacial de las concentraciones de hierro $(\mu \mathrm{g} / \mathrm{g})$ encontradas en los sedimentos superficiales del sector Guanta-Pertigalete, 11 Marzo de 1999. 162

Figura 32.- Distribución espacial de las concentraciones de manganeso $(\mu \mathrm{g} / \mathrm{g})$ encontradas en los sedimentos superficiales del sector Guanta-Pertigalete, 11 Marzo de 1999 163

Figura 33.- Distribución espacial de las concentraciones de níquel $(\mu \mathrm{g} / \mathrm{g})$ encontradas en los sedimentos superficiales del sector Guanta-Pertigalete, 11 Marzo de 1999 163

Figura 34.- Distribución espacial de las concentraciones de cinc $(\mu \mathrm{g} / \mathrm{g})$ encontradas en los sedimentos superficiales del sector Guanta-Pertigalete, 11 Marzo de 1999. 
Figura 35.- Distribución espacial de las concentraciones de plomo $(\mu \mathrm{g} / \mathrm{g})$ encontradas en los sedimentos superficiales del sector Guanta-Pertigalete, 11 Marzo de 1999 ............................................165 


\section{SECTOR GUANTA-PERTIGALETE}

\section{INTRODUCCIÓN}

Procedemos aquí a la descriptiva de la calidad de las aguas del sector Guanta-Pertigalete. El sector Guanta, tipificado por su bahía, es el asiento del margen costero de la ciudad de Guanta. La problemática de esta región se debe a una serie de factores sociales, humano y naturales. En primer lugar, allí se reciben las descargas de aguas negras de la ciudad, sin ningún tipo de tratamiento. La población de pescadores conocida como Volcadero, explota el ecosistema con una creciente presión por el espacio y las innegables necesidades de satisfacción de alimentación y servicios. La forma semicerrada de la bahía trae como consecuencia un tiempo de residencia de las aguas prolongado. Todo ello aunado al evidente grado de marginalidad de la población han convertido a la bahía en un cuerpo de agua contaminado y no apto para el contacto humano.

El sector Pertigalete es el asiento de la empresa Vencemos, la cual explota los recursos de piedra caliza, muy abundantes en la región, para la producción de cementos. Paralelamente, allí se encuentran algunos sitios de interés turísticos: Isla de Plata, Pamatacualito, ..etc. Dinámicamente esta bahía está más ventilada que la de Guanta, lo cual se evidencia por la claridad y transparencia de sus aguas.

\section{AREA DE ESTUDIO}

El Sector Guanta Pertigalete se encuentra ubicado en el margen costero Nor-oriental del Estado Anzoátegui. En términos geográficos está inscrito dentro del cuadrante (10¹4' 17.52" - 10¹5'40.68") Norte y $\left(64^{\circ} 33^{\prime} 6.48^{\prime \prime} 64^{\circ} 36^{\prime} 00^{\prime \prime}\right)$ Oeste.

\section{ADQUISICIÓN Y UBICACIÓN DE LOS PUNTOS DE MUESTREOS.}

Para la caracterización de las bahías de Guanta y Pertigalete (Figura 1) se realizó una visita al sector dentro del período sequía (11 de marzo de 1999). Se colectaron muestras de agua superficial en 21 estaciones y 14 para los estudios de sedimentos. La distribución de las estaciones trata de cubrir la totalidad del área, pero se hizo mayor énfasis en las zonas costeras que poseían evidencias visuales y en ocasiones olfativas de contaminación. 


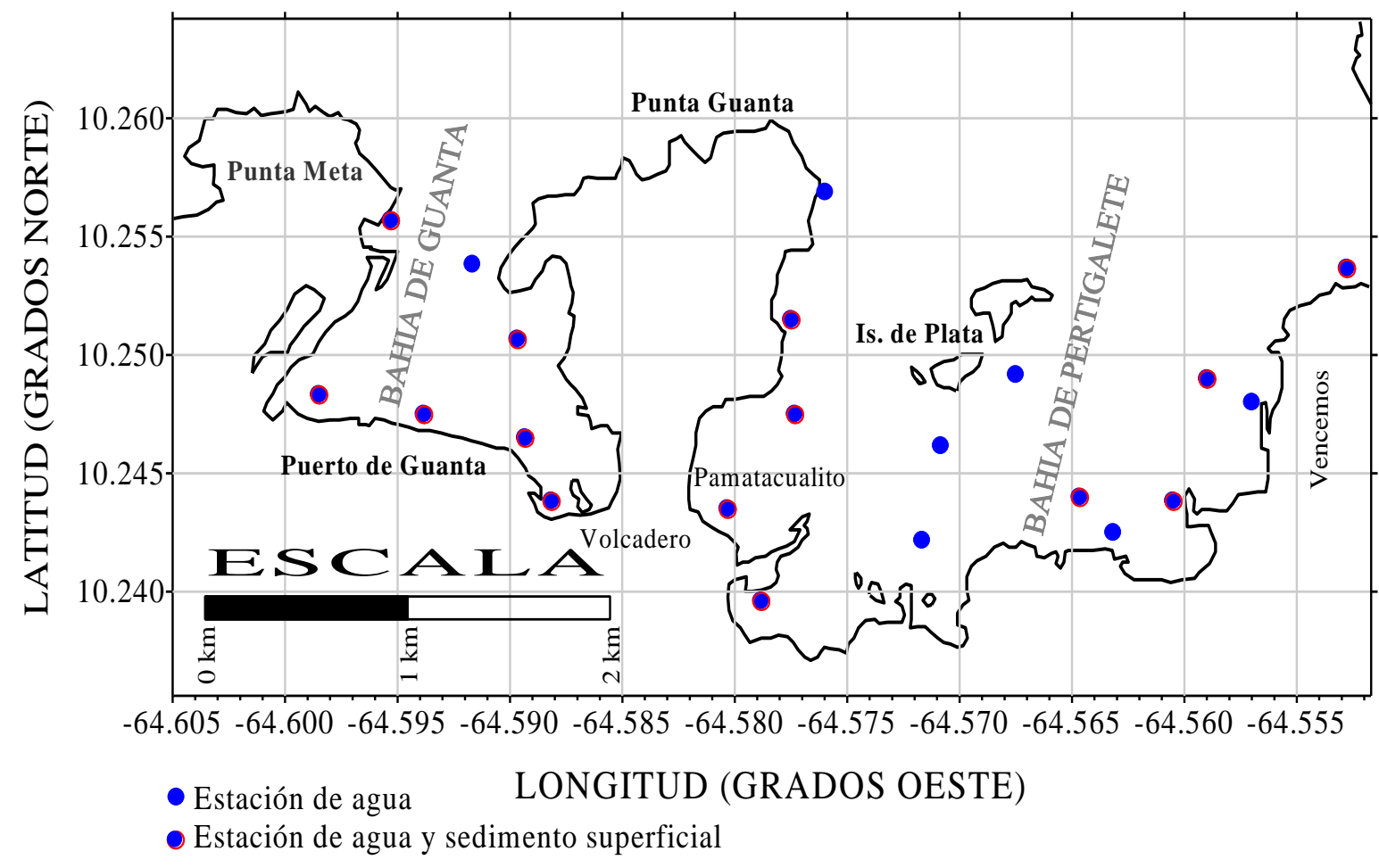

Figura 1.- Localización espacial de las estaciones de muestreo. Los círculos azules llenos representan las estaciones de aguas, los círculos azules con borde rojo representas las estaciones simultáneas de agua y sedimento.

\section{CARACTERISTICAS HIDROLOGICAS}

\section{TEMPERATURA}

Los valores de temperatura registrados estuvieron comprendidos entre $25,4^{\circ} \mathrm{C}$ y $27,7^{\circ} \mathrm{C}$, con un valor medio de $26,02{ }^{\circ} \mathrm{C}$ (Figura 2). Destaca en la distribución espacial la presencia de zonas de valores máximos hacia las zonas de Pamatacualito, Volcadero y el sector sur occidental de la bahía de Guanta, donde descargan las aguas servidas a través del Drenaje $\mathrm{C}$ de la ciudad de Puerto La Cruz. En el resto de las áreas examinadas éste parámetro presentó una distribución bastante homogénea. 


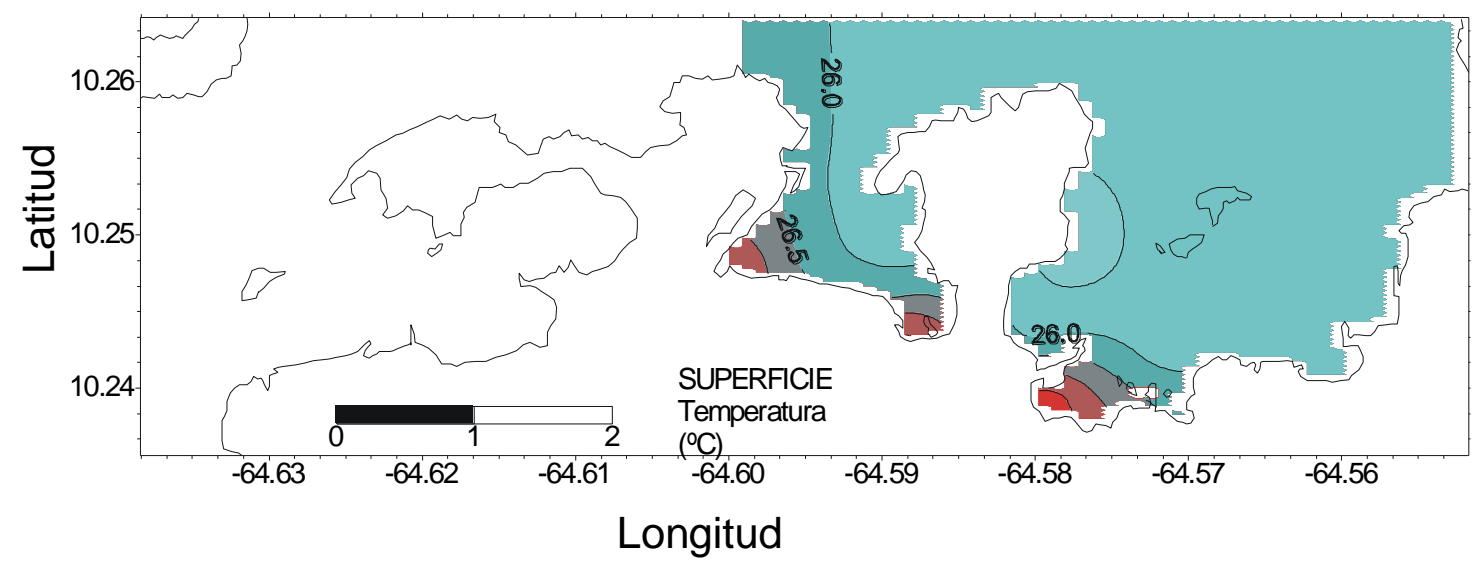

Figura 2.- Distribución espacial de la temperatura superficial $\left({ }^{\circ} \mathrm{C}\right)$ en el sector Guanta Pertigalete., 11 de marzo de 1999.

\section{SALINIDAD}

Los valores de salinidad registrados variaron entre 36,096 y 37,043 , con un valor promedio de 36,872 (Figura 3). Hay que resaltar la presencia de disminuciones de la salinidad en el sector de descarga del Drenaje $\mathrm{C}$ de uno de los colectores de lluvia de la ciudad de Puerto La Cruz, y hacia el sector conocido como Volcadero, donde llegan al ecosistema innumerables vertidos de aguas negras.

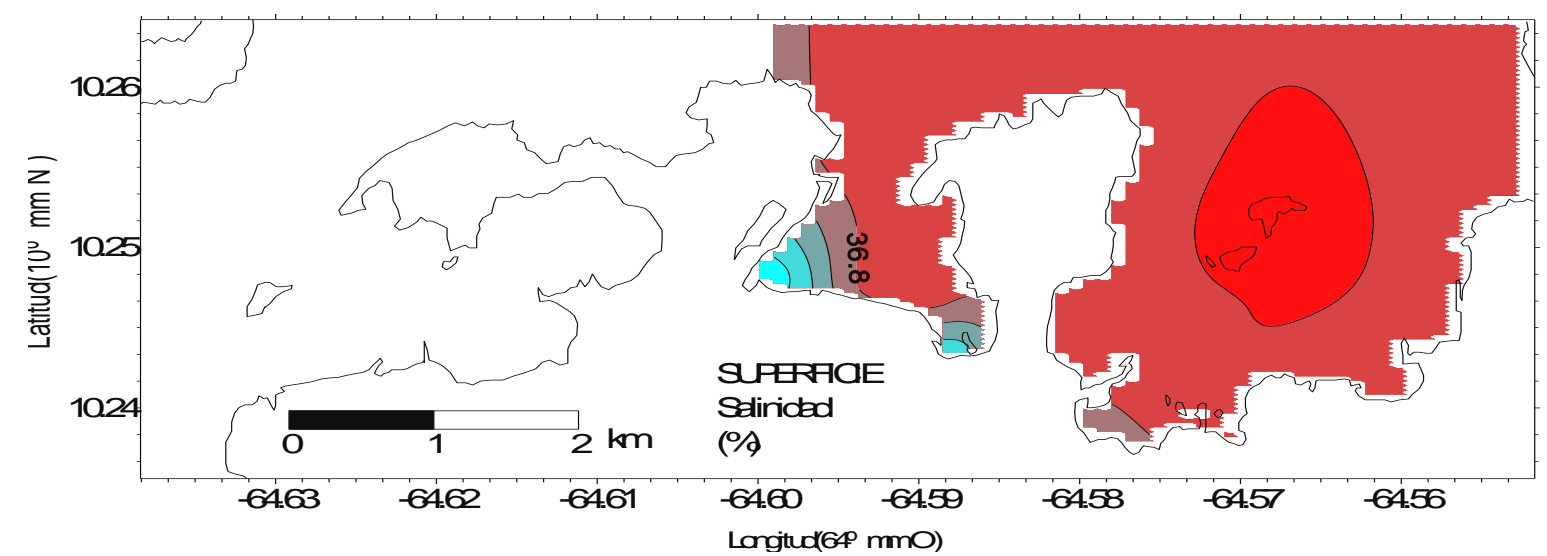

Figura 3.- Distribución espacial de la salinidad superficial (sin unidades) en el sector Guanta Pertigalete. 11 de Marzo de 1999.

\section{OXIGENO DISUELTO}

La distribución del oxígeno disuelto es presentada en la figura 4.. Las aguas presentaron buena oxigenación durante este muestreo. Las concentraciones detectadas estuvieron comprendidas entre $5,84 \mathrm{mg} / \mathrm{l}$ y 7,43 mg/l, con un valor promedio de 6,56 mg/l. Las más bajas concentraciones de oxígeno disuelto se ubicaron en la bahía de Pertigalete, y hacia el sector Volcadero, en la bahía de Guanta. 
Estas disminuciones de las concentraciones estarían asociadas a la carga de materia orgánica de las aguas superficiales.

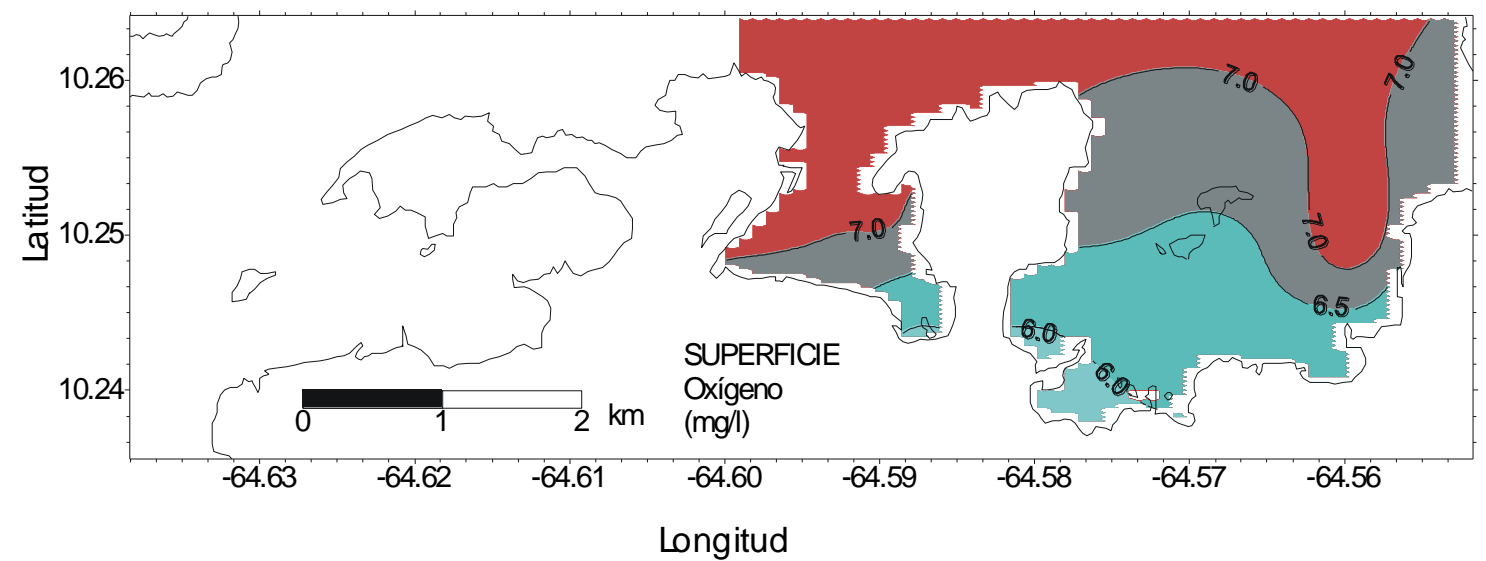

Figura 4.- Distribución espacial del oxígeno disuelto (mg/l) en el sector Guanta Pertigalete, 11 Marzo de 1999

$\mathrm{pH}$

Los valores de $\mathrm{pH}$ registrados en la zona se consideran normales para este tipo de ecosistema (Figura 5). El rango de variación tuvo como límites inferiores y superiores las cantidades de 7,86 y 8,25; respectivamente con un promedio de 7,99 unidades.

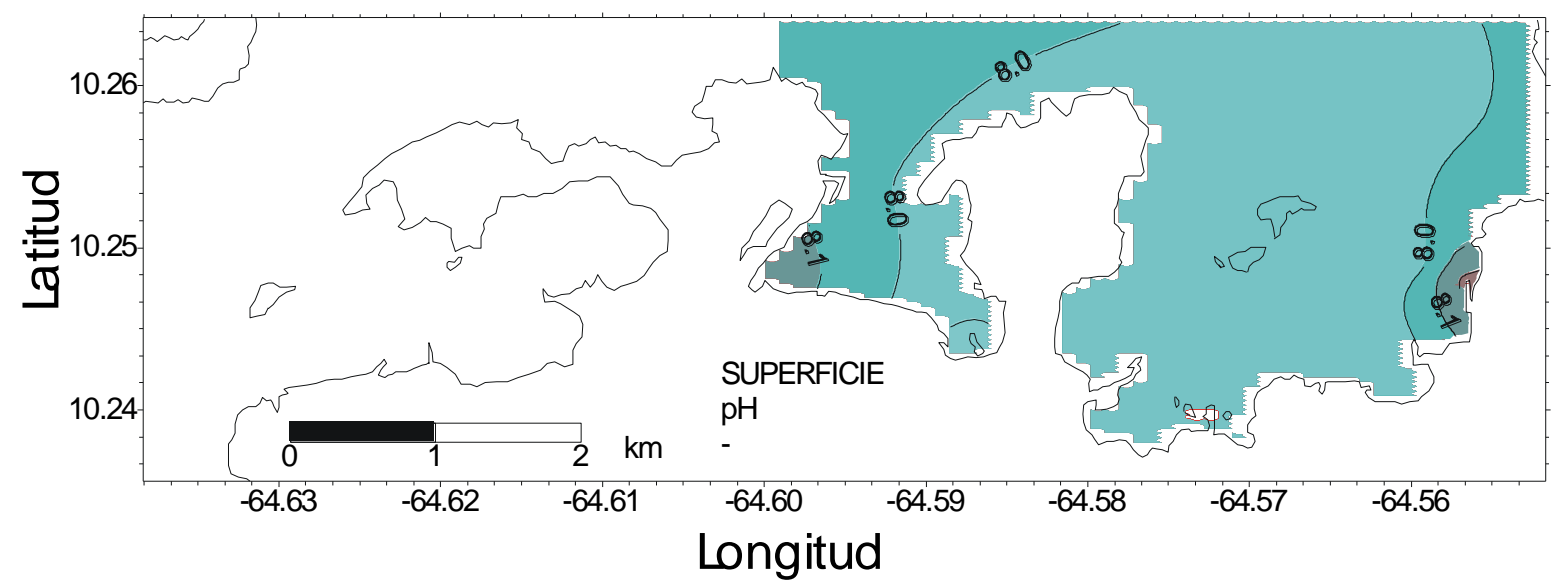

Figura 5.- Distribución espacial del pH superficial (mg/l) en el sector Guanta Pertigalete, 11 Marzo de 1999

\section{ELEMENTOS NUTRITIVOS}

\section{COMPUESTOS NITROGENADOS}

En las figuras 6, 7 y 8 se presenta la distribución del amonio, nitrato (+ nitrito) y del nitrógeno total. Se puede apreciar la existencia de una distribución bastante uniforme de cada uno de estos parámetros. 
Sin embargo, hay que resaltar el incremento de las concentraciones de estos elementos en los sectores de descarga del Drenaje C y Volcadero, en la bahía de Guanta, así como en las cercanías de la planta de cementos de vencemos, en la bahía de Pertigalete. Las concentraciones de amonio superan en Guanta los $8 \mu \mathrm{mol} / \mathrm{l}$, lo cual pone en evidencia el aporte de aguas altamente contaminadas provenientes de las descargas de aguas negras a través del Drenaje $C$ y de la población de Guanta, en el sector de Volcadero. Así mismo, se detectaron concentraciones de nitrógeno total que superaron los $45 \mu \mathrm{mol} / /$ en estas zonas. El vertido de aguas de elevada carga orgánica es puesto de manifiesto en el emisario proveniente de la planta de cementos, donde las concentraciones de nitrógeno total superaron los $55 \mu \mathrm{mol} / \mathrm{l}$.

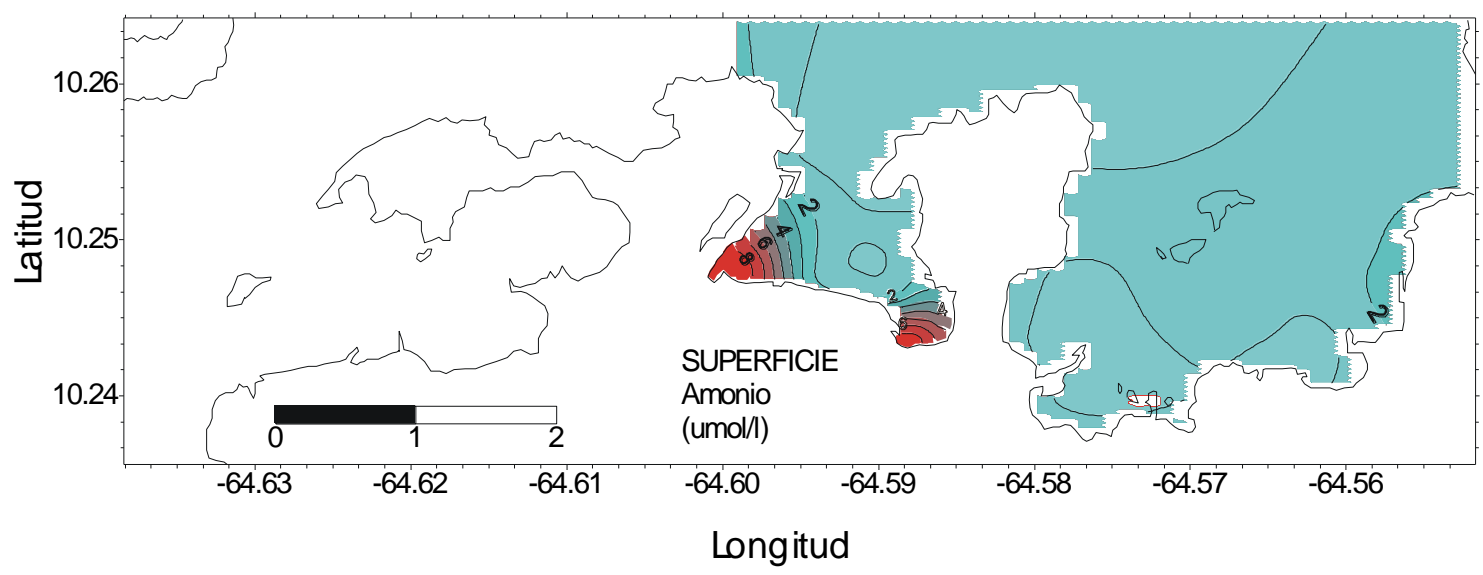

Figura 6.- Distribución espacial del Amonio superficial ( $\mu \mathrm{mol} / \mathrm{l})$ en el sector Guanta Pertigalete, 11 Marzo de 1999 


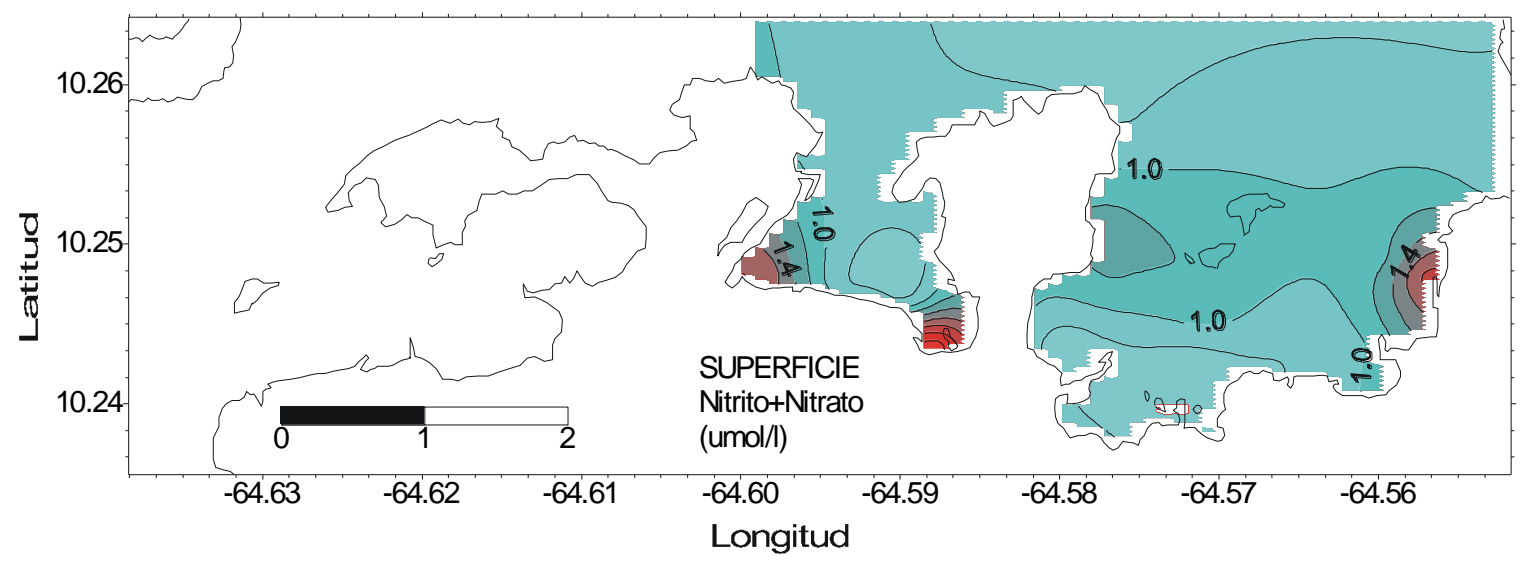

Figura 7- Distribución espacial del Nitrito + Nitrato superficial ( $\mu \mathrm{mol} / \mathrm{l})$ en el sector Guanta Pertigalete, 11 Marzo de 1999

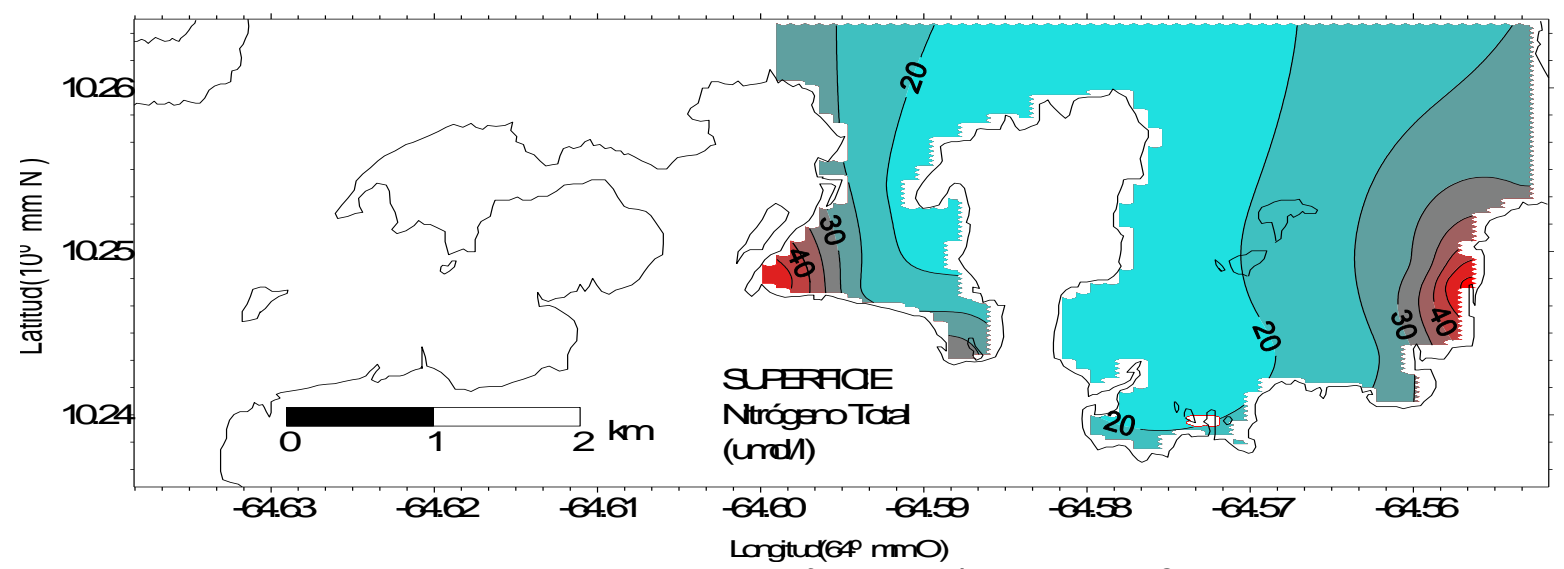

Figura 8.- Distribución espacial del Nitrógeno Total superficial ( $\mu \mathrm{mol} / \mathrm{l})$ en el sector Guanta Pertigalete, 11 Marzo de 1999

\section{COMPUESTOS DE FÓSFORO}

Las figuras 9 y 10 presentan la distribución del fosfato y del fósforo total respectivamente. Se aprecia claramente la existencia de un aporte importante de estos elementos al ecosistema de la bahía de Guanta, por intermedio del Drenaje C, donde se registraron valores de fosfato por encima de 1,6 $\mu \mathrm{mol} / \mathrm{l}$, $y$ de fósforo total superiores a $4 \mu \mathrm{mol} / \mathrm{l}$. En el resto del ecosistema los valores registrados fueron bastante bajos y homogéneamente repartidos, con pequeños incrementos en el sector de Volcadero. 


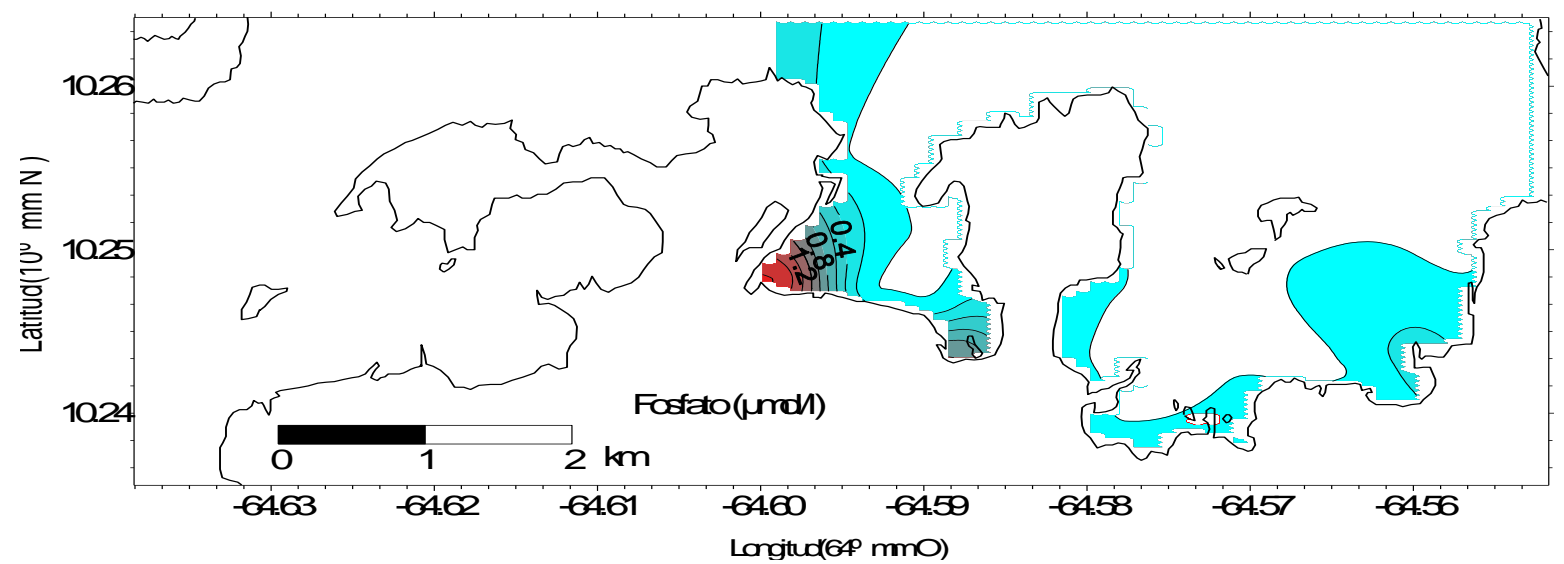

Figura 9- Distribución espacial del fosfato superficial ( $\mu \mathrm{mol} / /)$ en el sector Guanta Pertigalete, 11 Marzo de 1999

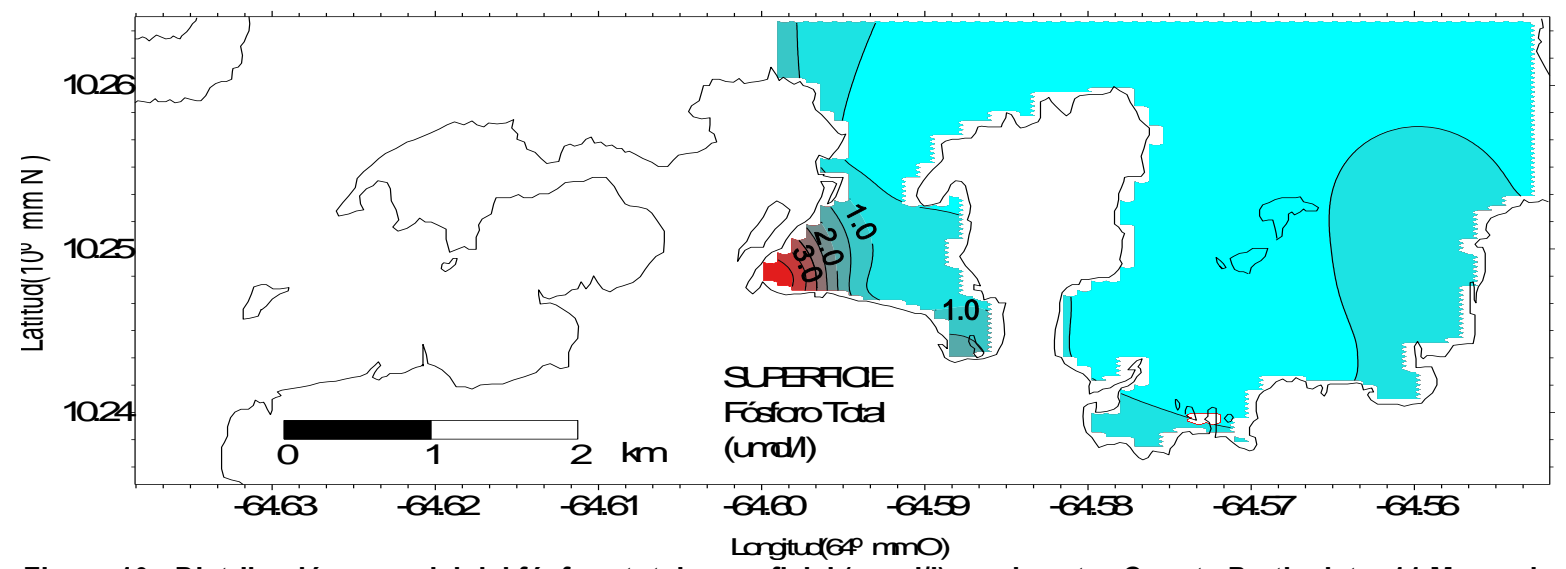

Figura 10.- Distribución espacial del fósforo total superficial ( $\mu \mathrm{mol} / \mathrm{l})$ en el sector Guanta Pertigalete, 11 Marzo de 1999

\section{CALIDAD DE LAS AGUAS}

\section{SOLIDOS SUSPENDIDOS}

Las concentraciones de sólidos suspendidos estuvieron comprendidas entre 16 y $43 \mathrm{mg} / \mathrm{l}$, con un valor promedio de $21 \mathrm{mg} / \mathrm{l}$ (Figura 11). Las más elevadas concentraciones se ubicaron en la bahía de Guanta, hacia el sitio de descarga del Drenaje C y en el sector de Volcadero. 


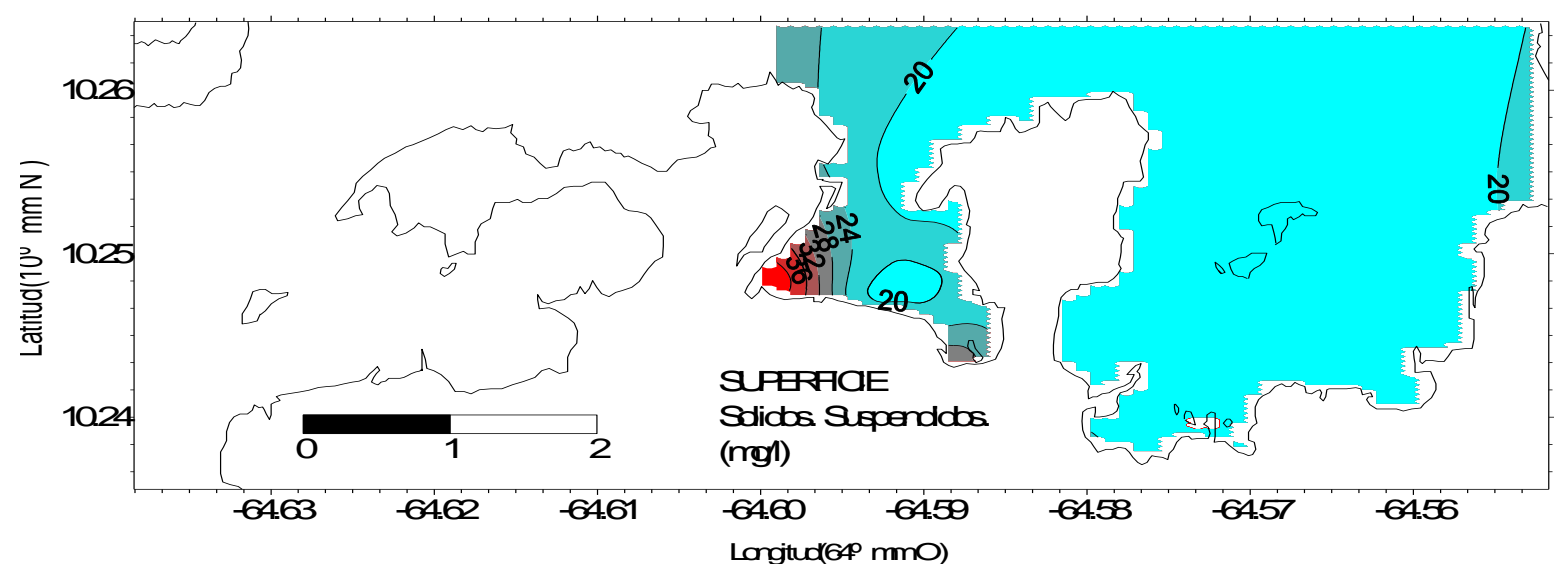

Figura 11- Distribución espacial de los sólidos suspendidos $(\mathrm{mg} / \mathrm{l})$ en las aguas superficiales en el sector Guanta Pertigalete, 11 Marzo de 1999

\section{ORGANISMOS COLIFORMES}

Es esencialmente hacia el sector conocido como Volcadero, en Guanta, donde se registraron las más elevadas concentraciones de organismos coliformes (Figuras 12 y 13), poniendo de manifiesto el estado de deterioro de esta bahía de gran importancia turística y comercial.

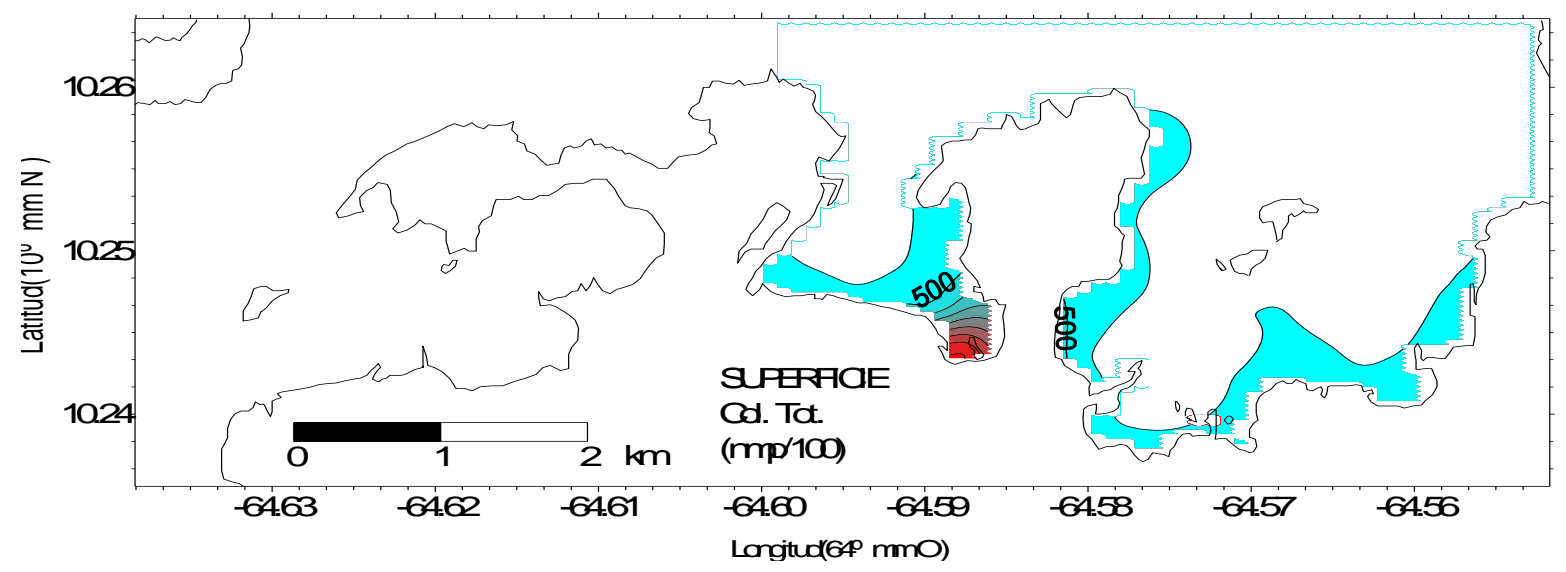

Figura 12.- Distribución espacial de los coliformes fecales (NMP/100 ml) en las aguas superficiales del sector Guanta Pertigalete, 11 Marzo de 1999. 


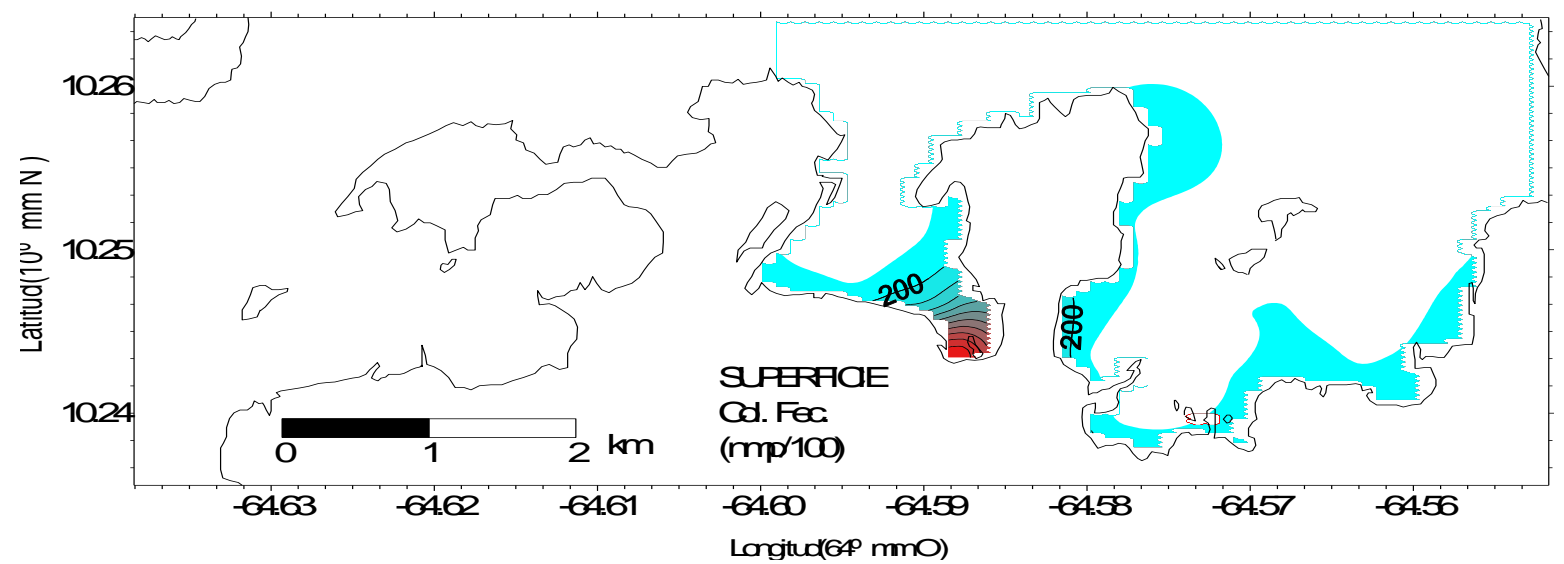

Figura 13.- Distribución espacial de los coliformes fecales (NMP/100 ml) en las aguas superficiales del sector Guanta Pertigalete, 11 Marzo de 1999.

\section{DEMANDA BIOQUIMICA DE OXIGENO $\left(\mathrm{DBO}_{5}\right)$}

Las concentraciones de DBO5 fueron bastante variables en las aguas superficiales de Guanta y Pertigalete (Figura 14). Las concentraciones estuvieron comprendidas entre 18 y $47 \mathrm{mg} / \mathrm{l}$, con valores promedios de $26 \mathrm{mg} / \mathrm{l}$. Nuevamente se detectan concentraciones elevadas hacia el sector de Volcadero, así como hacia la región de Pamatacualito, donde las concentraciones alcanzaron los valores máximos. En esta última región estamos en presencia de una gran abundancia de manglar, y se caracteriza por bajas profundidades. La elevada productividad del ecosistema de manglar pudiese estar al origen de este incremento de las concentraciones.

En la figura se puede apreciar la presencia de aguas con concentraciones de DBO5 superiores a 35 $\mathrm{mg} / \mathrm{l}$, en el sector oriental de la bahía de Pertigalete, probablemente aportados desde la bahía de Conoma. 


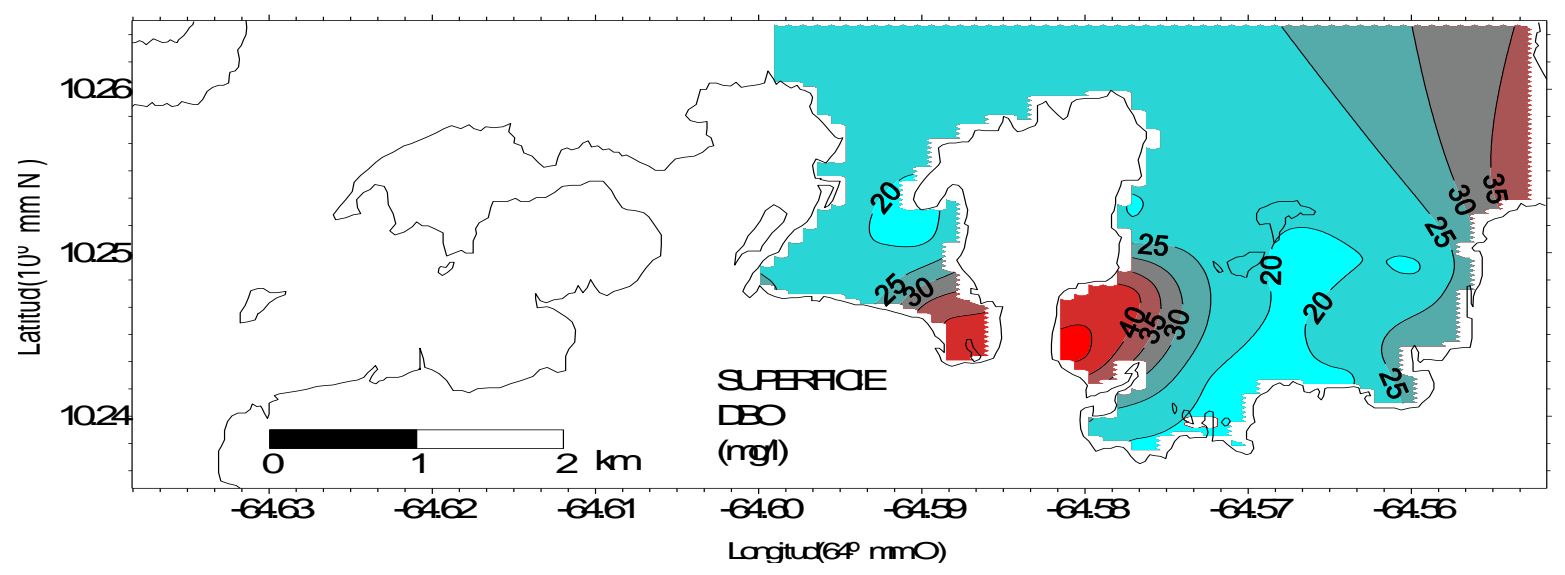

Figura 14- Distribución espacial de la demanda biológica de oxígeno ( $\mathrm{mg} / \mathrm{l})$ en las aguas superficiales del sector Guanta-Pertigalete, 11 Marzo de 1999.

\section{ACEITES Y GRASAS}

Los aceites y grasas presentaron bajas concentraciones en todo el ecosistema, con la excepción del sector oriental de la bahía de Guanta, donde se registraron concentraciones por encima de los 1,8 mg/l (Figura 15). Estas elevadas concentraciones son originadas por la actividad portuaria y de reparación de embarcaciones que tiene lugar en la región, así como por la gran afluencia de embarcaciones tipo peñero.

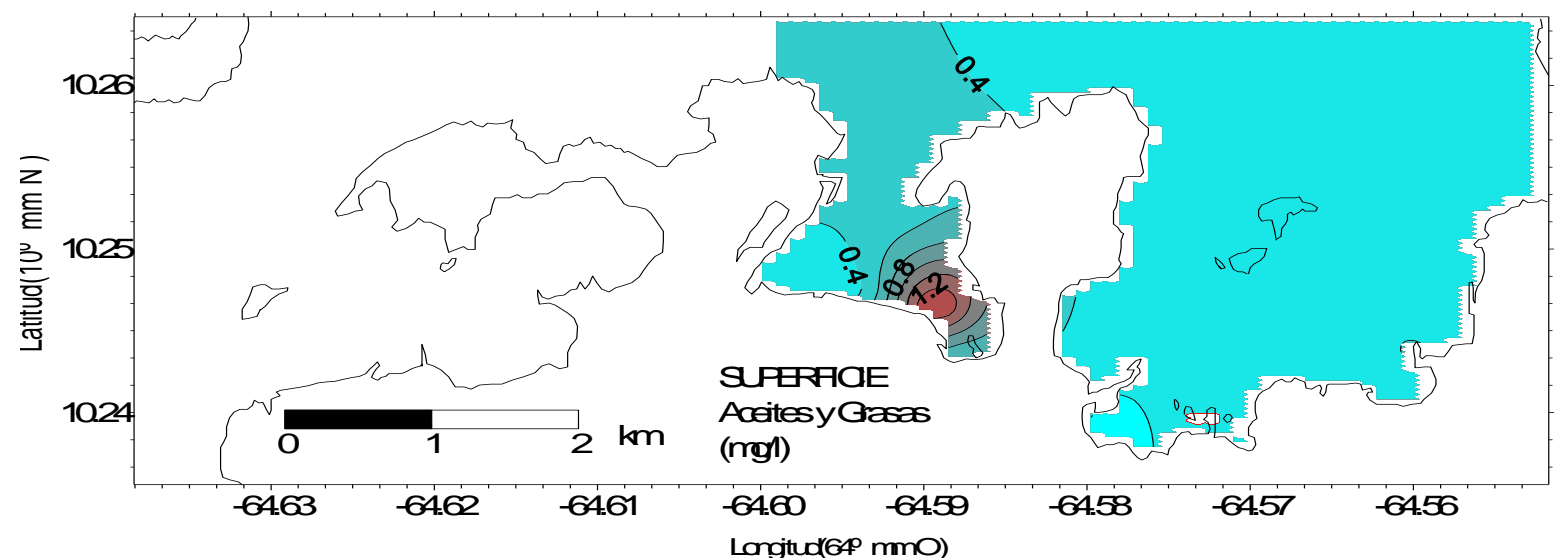

Figura 15- Distribución espacial de los aceites y grasas (mg/l) en las aguas superficiales del sector GuantaPertigalete, 11 Marzo de 1999. 


\section{DETERGENTES}

La distribución de este parámetro fue bastante irregular (Figura 16). Las concentraciones estuvieron comprendidas entre $0,01 \mathrm{mg} / \mathrm{l}$ y $0,19 \mathrm{mg} / \mathrm{l}$. Se pudo apreciar la existencia de diversas fuentes de estos elementos al ecosistema. Concentraciones superiores a $0,16 \mathrm{mg} / \mathrm{l}$ penetran hacia la región, presumiblemente desde la bahía de Pozuelos. Otro aporte importante se ubicó en el sector de Volcadero, donde las concentraciones detectadas superaron los $0,18 \mathrm{mg} / \mathrm{l}$, y hacia la población de Teleforo, ubicada en las cercanías de Punta de Guanta en la bahía de Pertigalete.

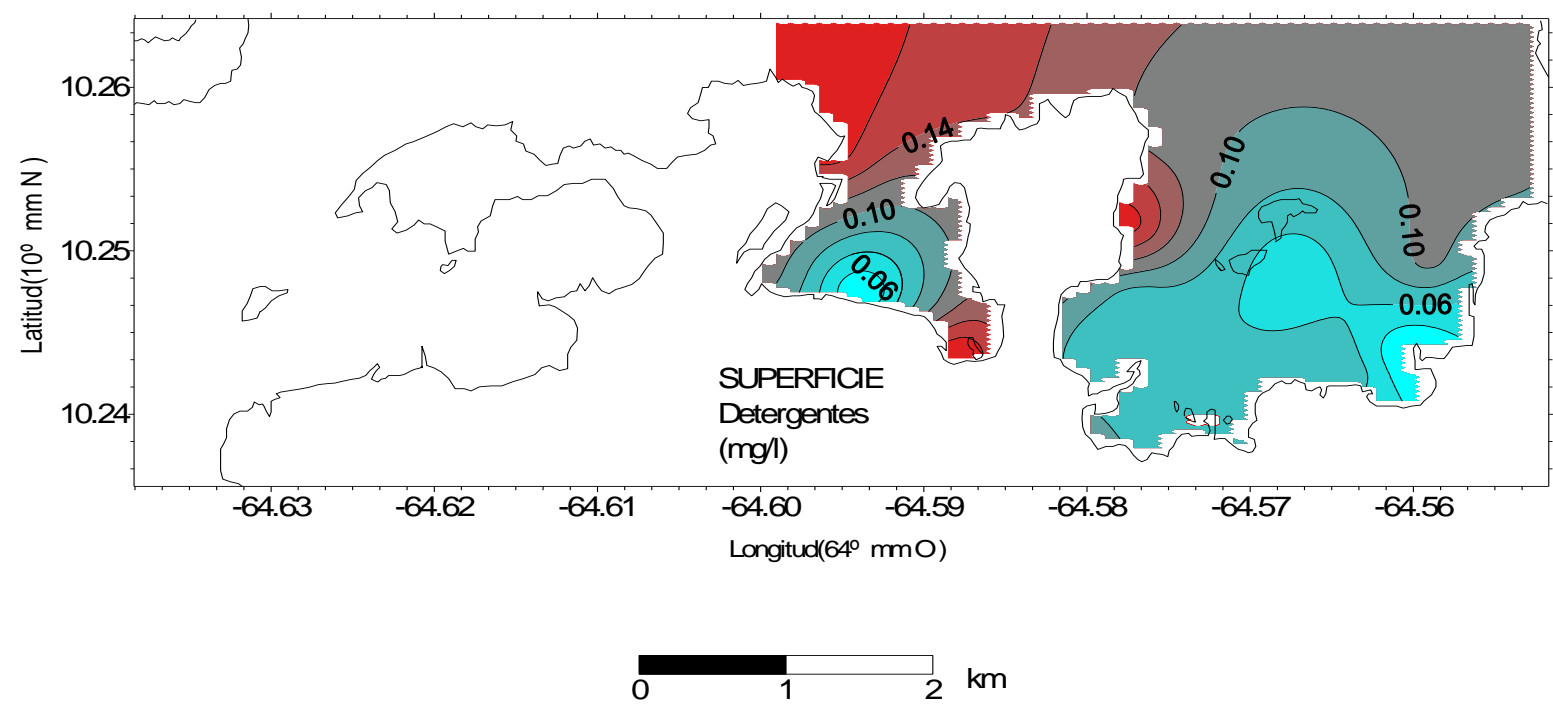

Figura 16- Distribución espacial de los detergentes (mg/l) en las aguas superficiales del sector GuantaPertigalete, 11 Marzo de 1999.

\section{METALES PESADOS}

La distribución del cinc, cobre y plomo es representada en las figuras 17,18 y 19, respectivamente. Estos tres elementos presentaron una distribución que espacialmente se correlaciona. Las mayores concentraciones se ubicaron hacia la bahía de Pertigalete, particularmente, hacia el sector oriental de la misma. Aparte de valores máximos que podrían provenir de la bahía de Conoma, se registró un núcleo de concentraciones superiores a $30 \mu \mathrm{g} / \mathrm{l}$ en la zona donde opera la planta de cementos Vencemos, asociado al incremento de los compuestos nitrogenados. Este núcleo de concentraciones se extendió hacia el sector de Isla de Plata, donde se detectaron valores superiores a $20 \mu \mathrm{g} / \mathrm{l}$. 
El cobre presentó las mismas características, con concentraciones superiores a $4 \mu \mathrm{g} / \mathrm{l}$, provenientes de la bahía de Conoma y valores por encima de $3 \mu \mathrm{g} / \mathrm{l}$ en las cercanías de la planta de cemento. Una segunda elevación de las concentraciones de este elemento se detectó en la zona de Pamatacualito, con concentraciones de $2,5 \mu \mathrm{g} / \mathrm{l}$.

En el caso del plomo se apreciaron las máximas concentraciones hacia el sector oriental de Pertigalete, disminuyendo sus concentraciones en dirección hacia el oeste.

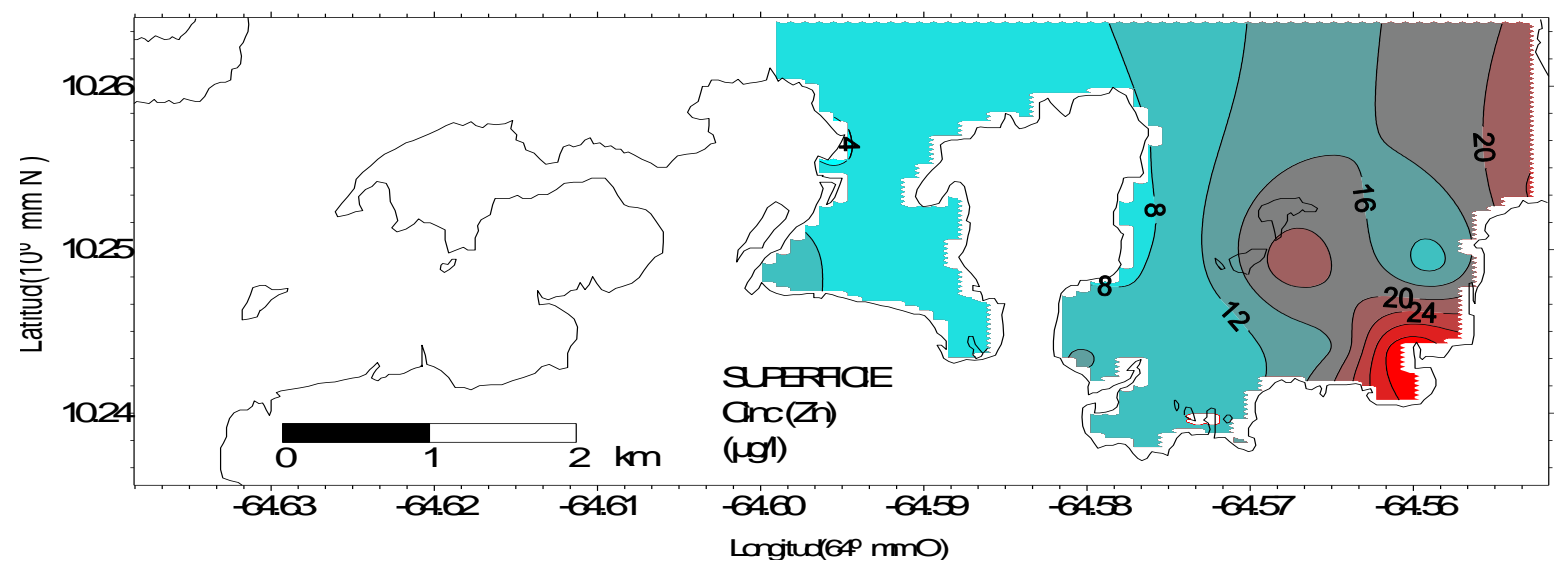

Figura 17- Distribución espacial del Cinc $(\mu \mathrm{g} / \mathrm{l})$ en las aguas superficiales del sector Guanta-Pertigalete, 11 Marzo de 1999.

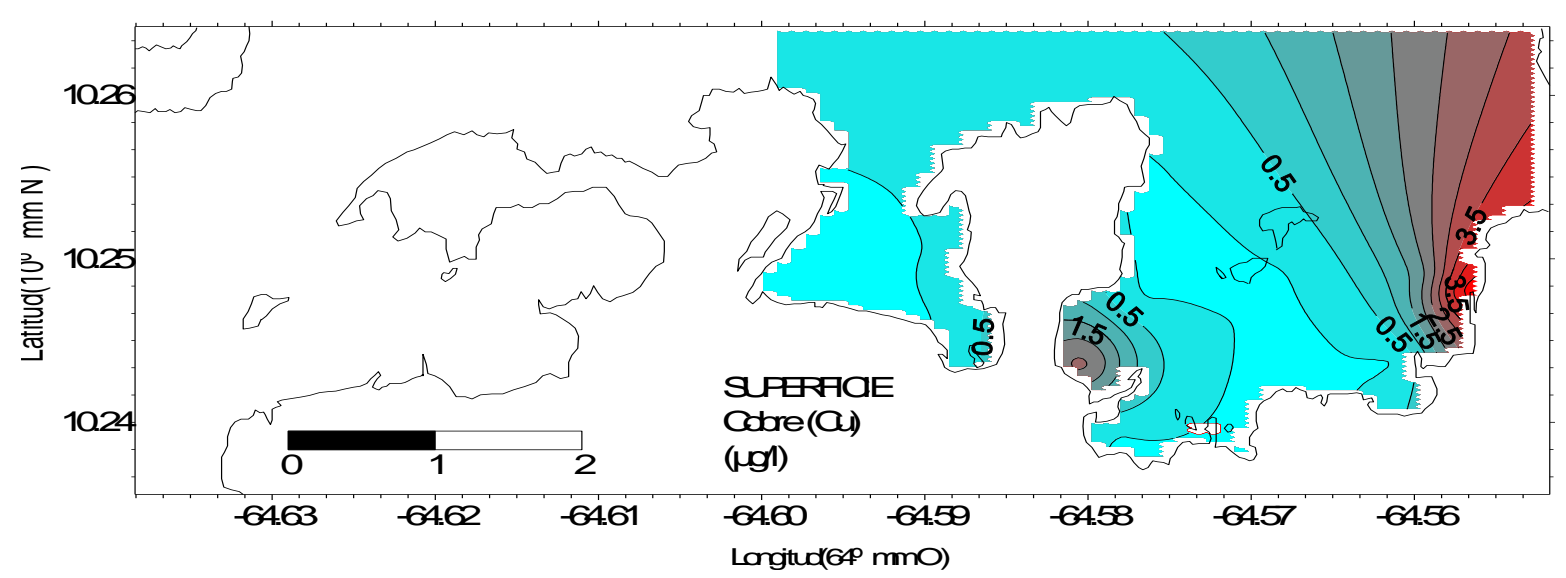

Figura 18.- Distribución espacial del cobre $(\mu \mathrm{g} / \mathrm{l})$ en las aguas superficiales del sector Guanta-Pertigalete, 11 Marzo de 1999. 


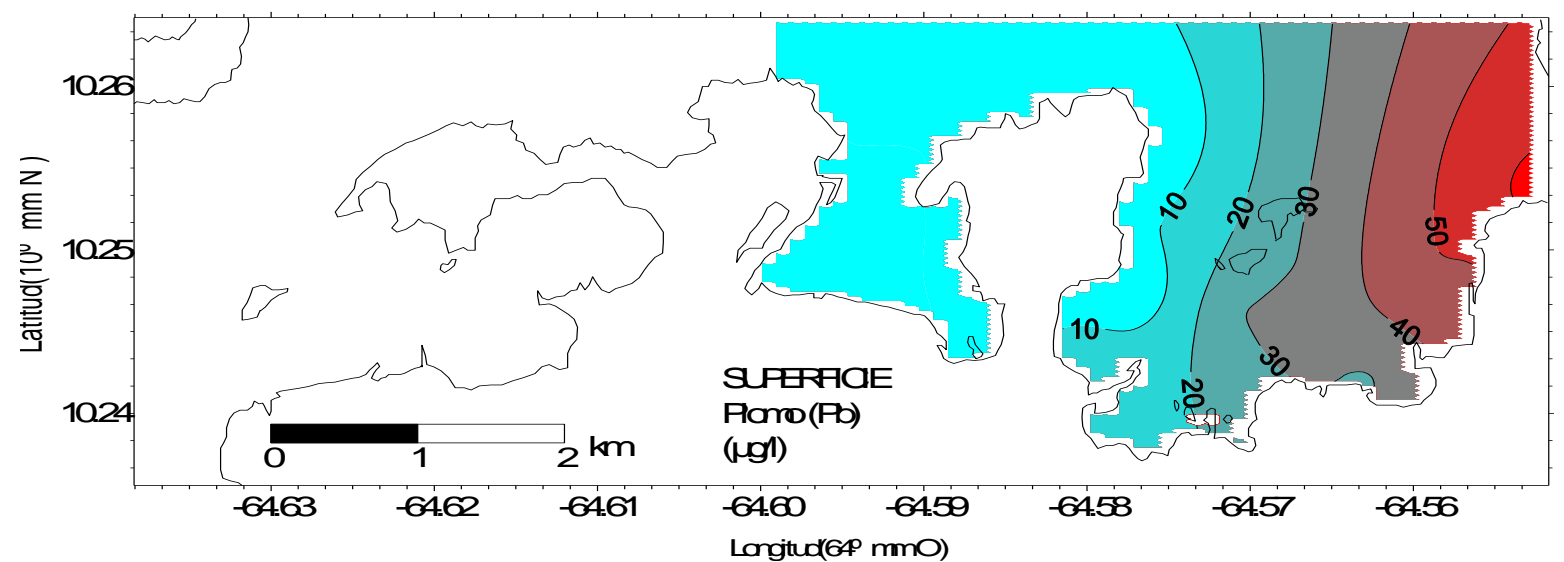

Figura 19.- Distribución espacial del plomo $(\mu \mathrm{g} / \mathrm{l})$ en las aguas superficiales del sector Guanta-Pertigalete, 11 Marzo de 1999.

Los metales cromo, hierro y manganeso (figuras 20, 21 y 22) presentaron una distribución muy diferente. A pesar de que el cromo mostró máximas concentraciones hacia la zona donde está ubicada la planta de cementos $(>5 \mu \mathrm{g} / \mathrm{l})$, se apreciaron, igualmente, núcleos de máximas concentraciones hacia el sector sur - occidental de la bahía de Pertigalete $(>5 \mu \mathrm{g} / \mathrm{l})$, y hacia el sector nor-occidental de la bahía de Guanta; sugiriendo la existencia de diferentes fuentes de este elemento al ecosistema examinado.

Las concentraciones de hierro fueron máximas hacia el sector occidental del área de estudio. La distribución de las isolíneas sugiere un aporte de este elemento desde la bahía de Pozuelos.

La distribución del manganeso fue bastante homogénea, con la excepción de un núcleo de concentraciones máximas detectadas a la entrada de la bahía de Guanta, donde las concentraciones registradas fueron superiores a $20 \mu \mathrm{g} / \mathrm{l}$.

La distribución de los elementos metálicos pone de manifiesto la existencia de diferentes vías de penetración de estos elementos a los ecosistemas examinados. Las actividades industriales y urbanas juegan un papel importante en estas distribuciones, así como los aportes atmosféricos, los cuales son considerados la principal vía de penetración de los metales a los ecosistemas acuáticos. 


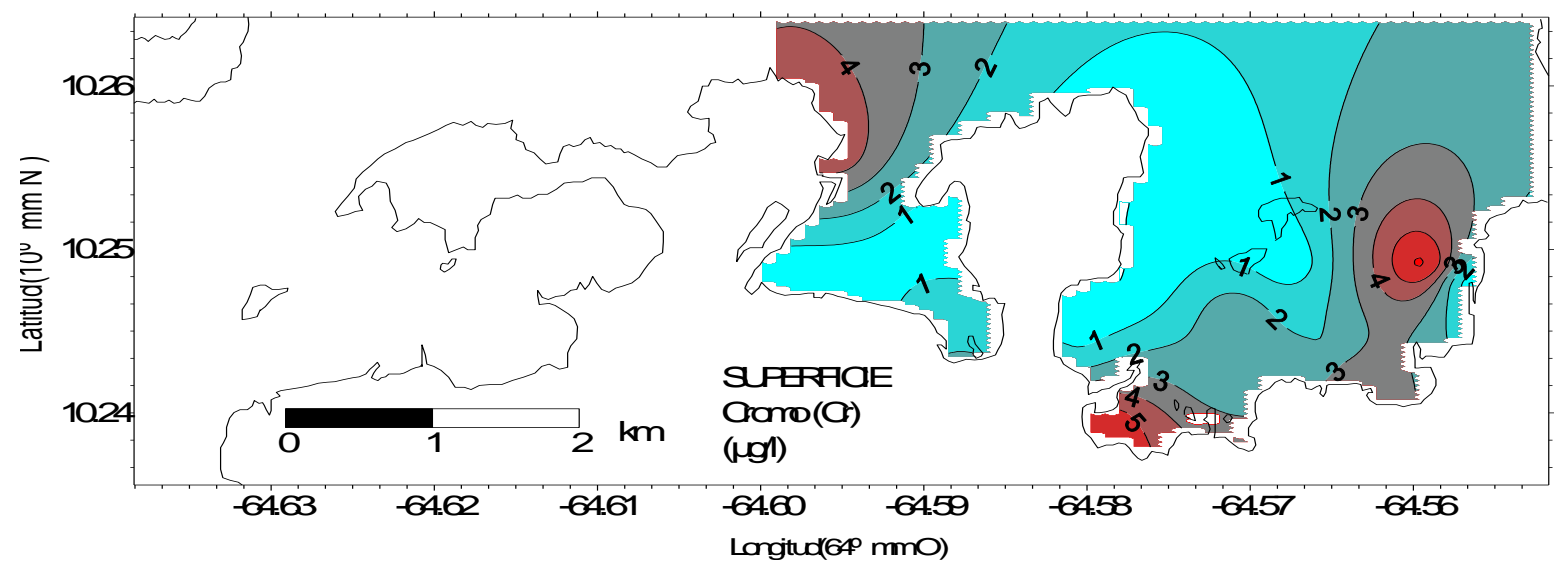

Figura 20.- Distribución espacial del cromo $(\mu \mathrm{g} / \mathrm{l})$ en las aguas superficiales del sector Guanta-Pertigalete, 11 Marzo de 1999.

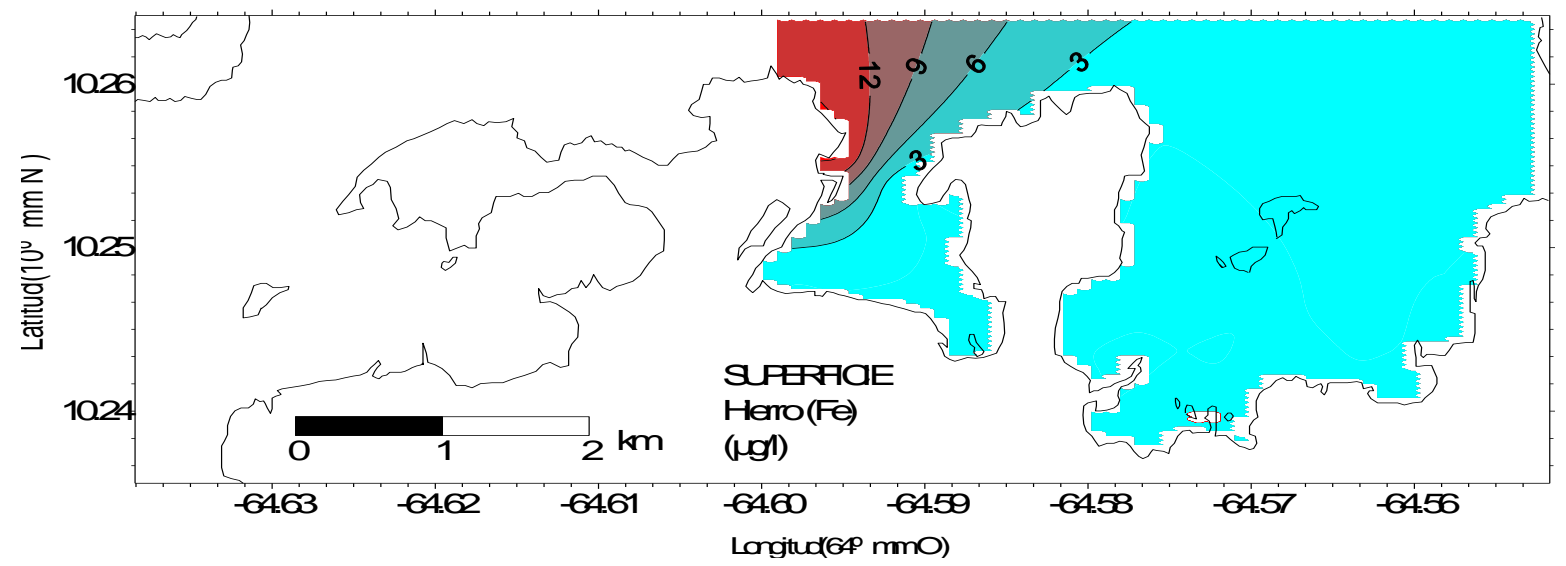

Figura 21.- Distribución espacial del hierro $(\mu \mathrm{g} / \mathrm{l})$ en las aguas superficiales del sector Guanta-Pertigalete, 11 Marzo de 1999.

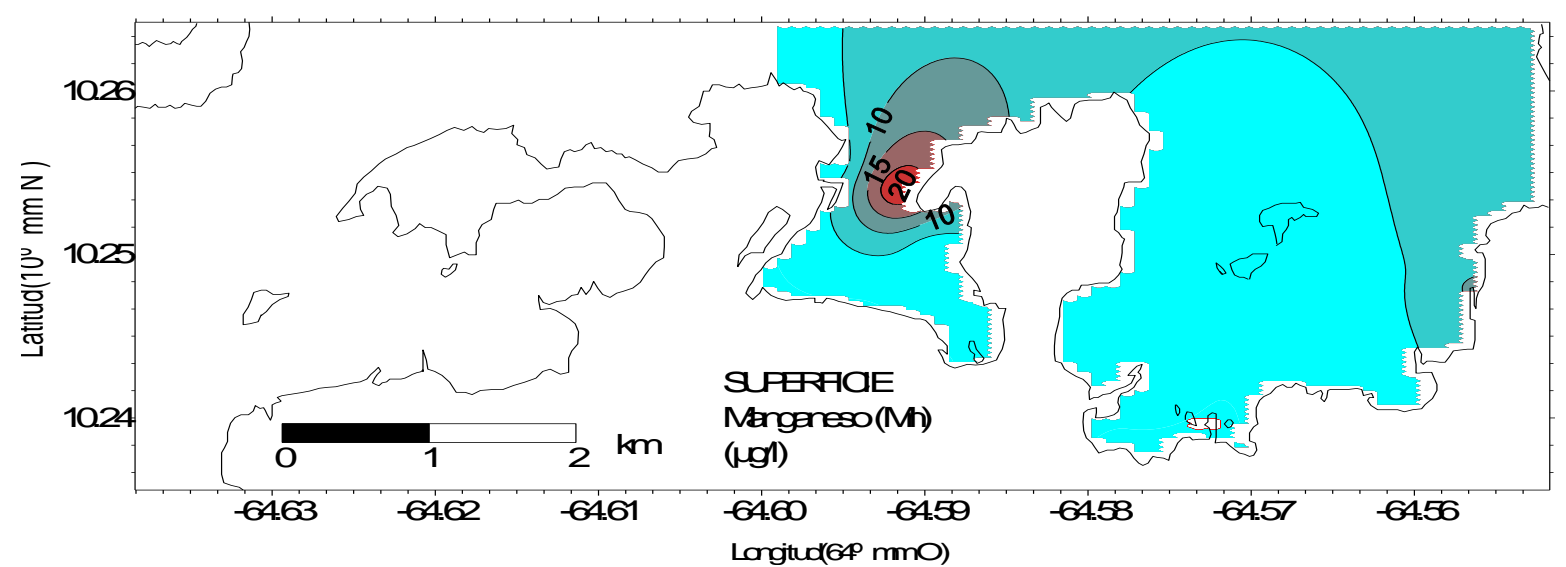

Figura 22- Distribución espacial del manganeso ( $\mu \mathrm{g} / \mathrm{l})$ en las aguas superficiales del sector Guanta-Pertigalete, 11 Marzo de 1999. 


\section{SEDIMENTOS SUPERFICIALES}

\section{TEXTURA SEDIMENTARIA}

Los sedimentos superficiales examinados presentaron una gran variabilidad en su textura (figuras 23 , 24 , y 25 ). Los porcentajes de arena variaron entre menos del $5 \%$ hasta más del $50 \%$. La zona costera presentó bajos porcentajes de arena, mientras que la predominancia de esta fue hacia el norte del ecosistema examinado. Toda la región costera presentó sedimentos con predominancia de limo y arcilla, como consecuencia de la predominancia de ecosistemas de manglar en la región.

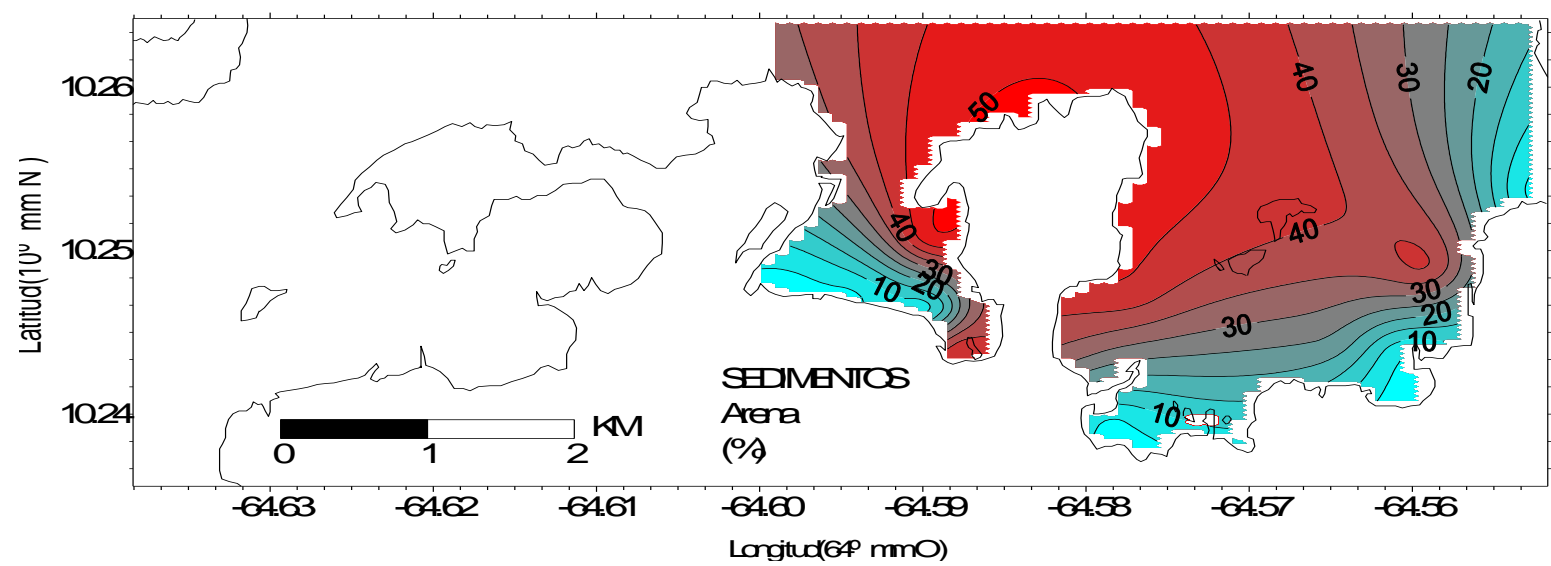

Figura 23.- Distribución espacial de los porcentajes de textura del sedimento: tipo arena sector GuantaPertigalete, 11 Marzo de 1999.

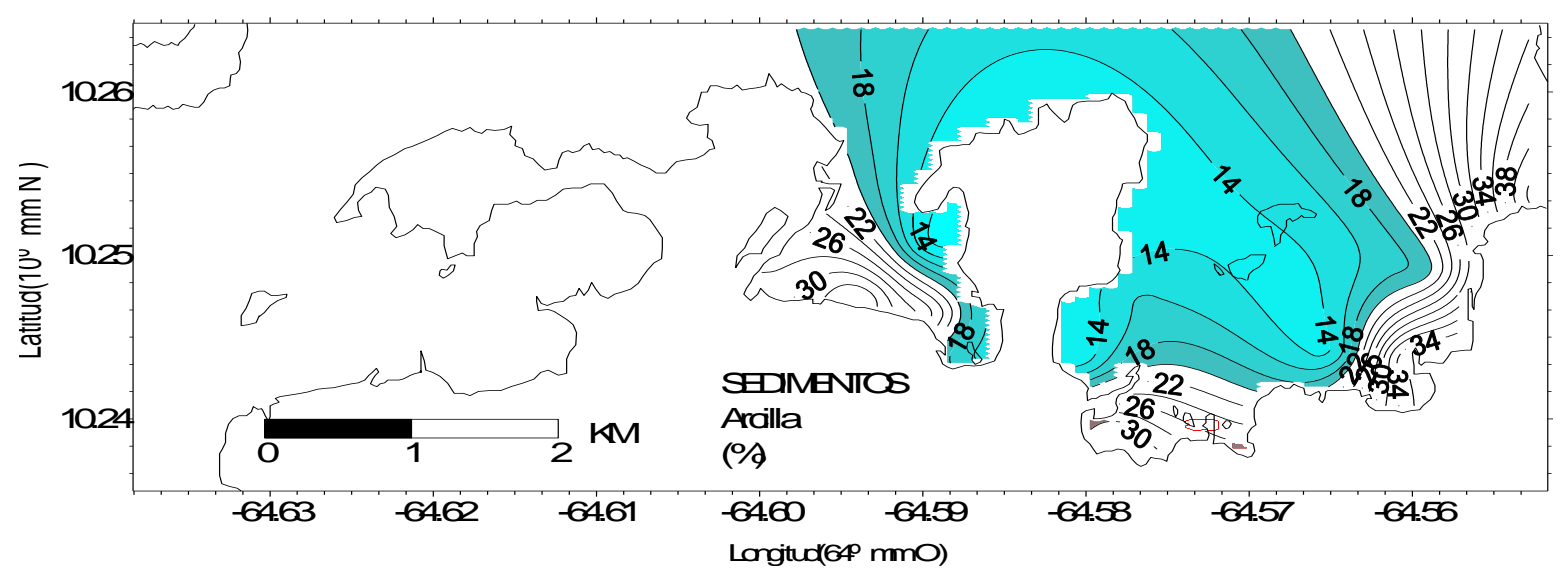

Figura 24.- Distribución espacial de los porcentajes de textura del sedimento: tipo arcilla sector GuantaPertigalete, 11 Marzo de 1999. 


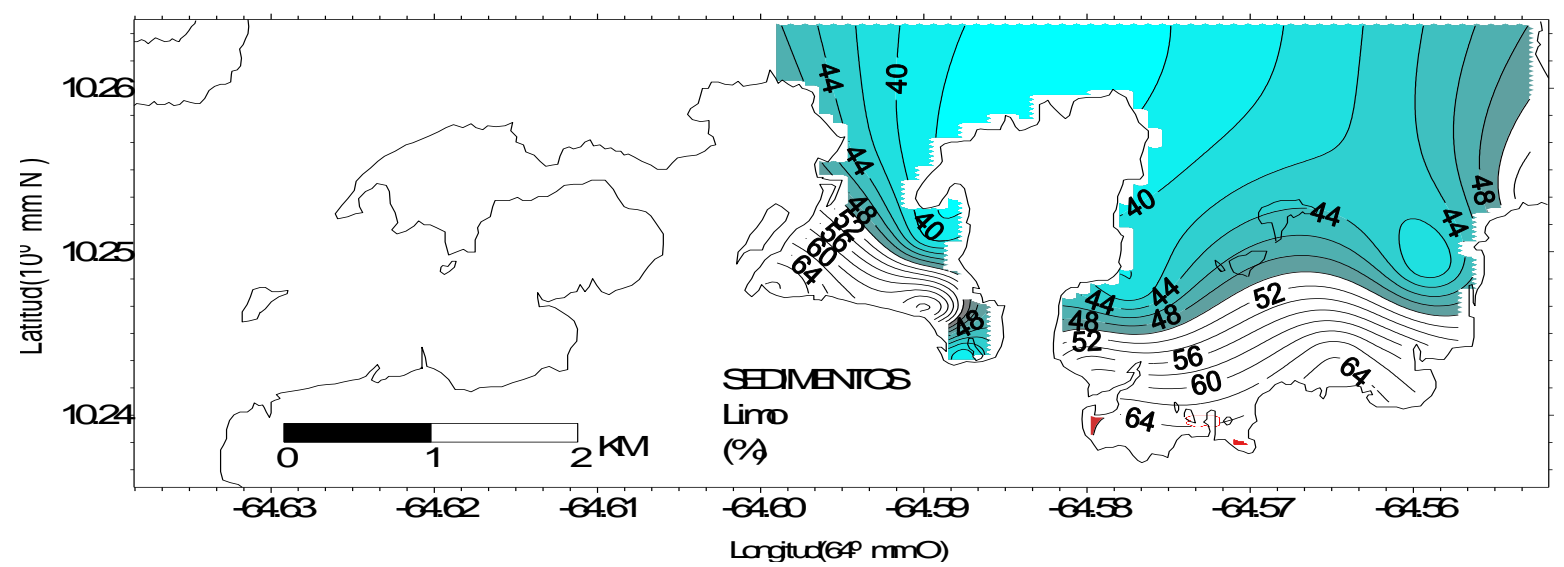

Figura 25.- Distribución espacial de los porcentajes de textura del sedimento: tipo limo sector GuantaPertigalete, 11 Marzo de 1999.

\section{CONTENIDO DE CARBONATOS}

La distribución del contenido de carbonatos es presentada en la figura 26. El porcentaje de este elemento fue elevado en casi la totalidad del área examinada, con valores superiores a $50 \%$. Los más bajos porcentajes se detectaron en la bahía de Guanta, en sus extremos oriental y occidental, donde los porcentajes cayeron por debajo del $30 \%$.

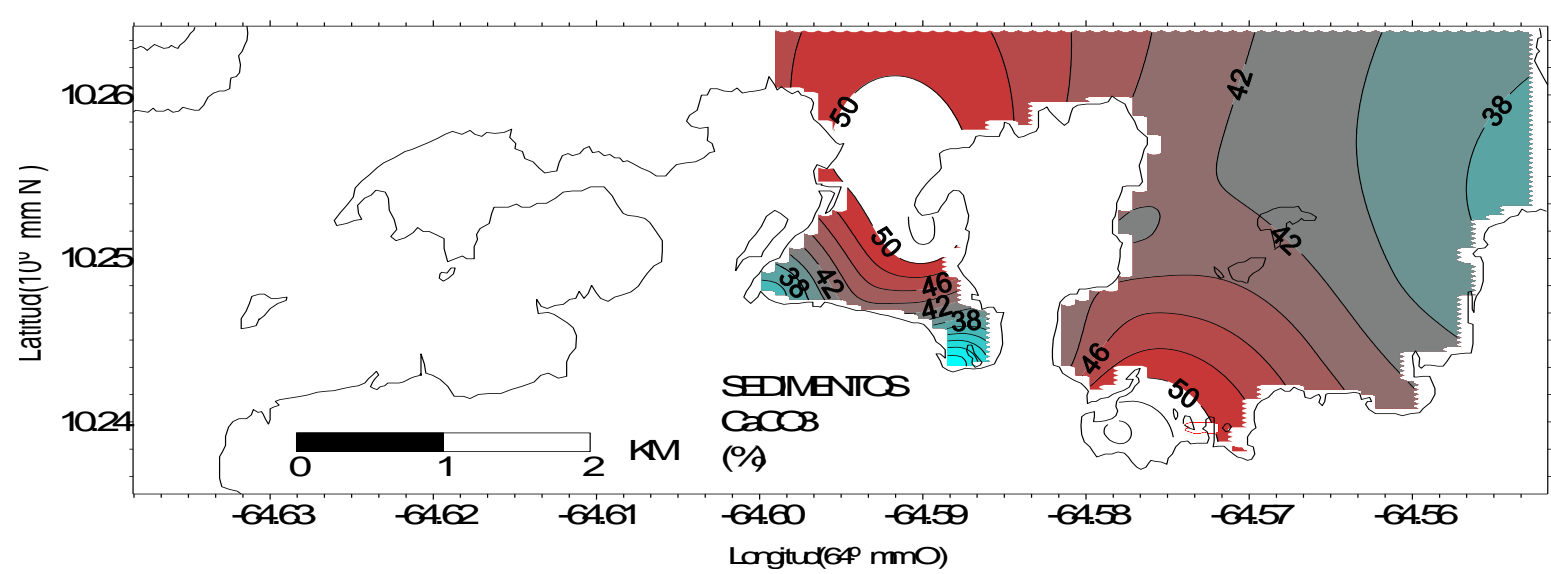

Figura 26- Distribución espacial de los porcentajes de textura del sedimento: tipo carbonato cálcico sector Guanta-Pertigalete, 11 Marzo de 1999. 


\section{ACEITES Y GRASAS}

Las concentraciones de aceites y grasas, en los sedimentos superficiales de las bahías de Guanta y Pertigalete, estuvieron homogéneamente repartidos. Gran parte del área examinada presentó concentraciones inferiores a $0,4 \mathrm{mg} / \mathrm{g}$ (Figura 27). Las concentraciones mayores de estos elementos se registraron en los sectores occidental y oriental de Guanta y en el sector de Pamatacualito, en Pertigalete. Concentraciones cercanas a 0,6 mg/g, se detectaron igualmente en las cercanías de la planta de cementos Vencemos.

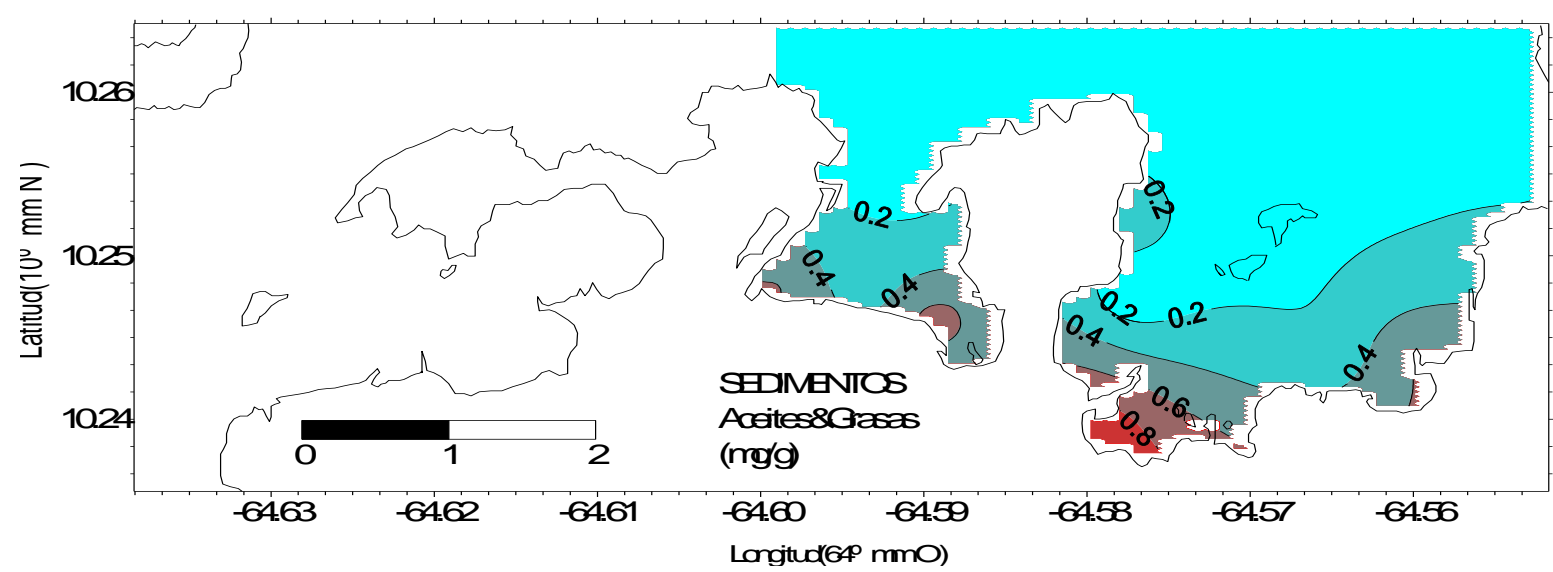

Figura 27- Distribución espacial de las concentraciones de aceites y grasas (mg/g) encontradas en los sedimentos superficiales del sector Guanta-Pertigalete, 11 Marzo de 1999.

\section{METALES PESADOS}

Los metales examinados presentaron una distribución que se correlaciona espacialmente una a otras, excepción del manganeso. Las concentraciones más elevadas detectadas se localizaron en el interior de las dos bahías, con máximos de concentraciones hacia los sectores sur oriental y occidental de Guanta y hacia el sector de Pamatacualito. Las concentraciones fueron bajas al norte de los dos ecosistemas examinados.

\section{Cadmio}

El cadmio evidencia gradientes de incrementos hacia las zonas menos ventiladas de ambas bahías. Las concentraciones estuvieron comprendidas entre 0,96 y $14,85 \mu \mathrm{g} / \mathrm{g}$, con un valor promedio de 4,19 
$\mu \mathrm{g} / \mathrm{g}$ (Figura 28). Las máximas concentraciones se ubicaron hacia el sector sur-occidental de la bahía de Pertigalete y sur-occidental de Guanta. Las concentraciones disminuyen de manera gradual a medida que nos dirigimos hacia el norte de las áreas, lejos de la influencia de las descargas de efluentes. Las áreas con elevadas concentraciones se encuentran impactadas por una actividad humana e industrial bastante importante, lo cual sugiere un origen mixto de estos compuestos.

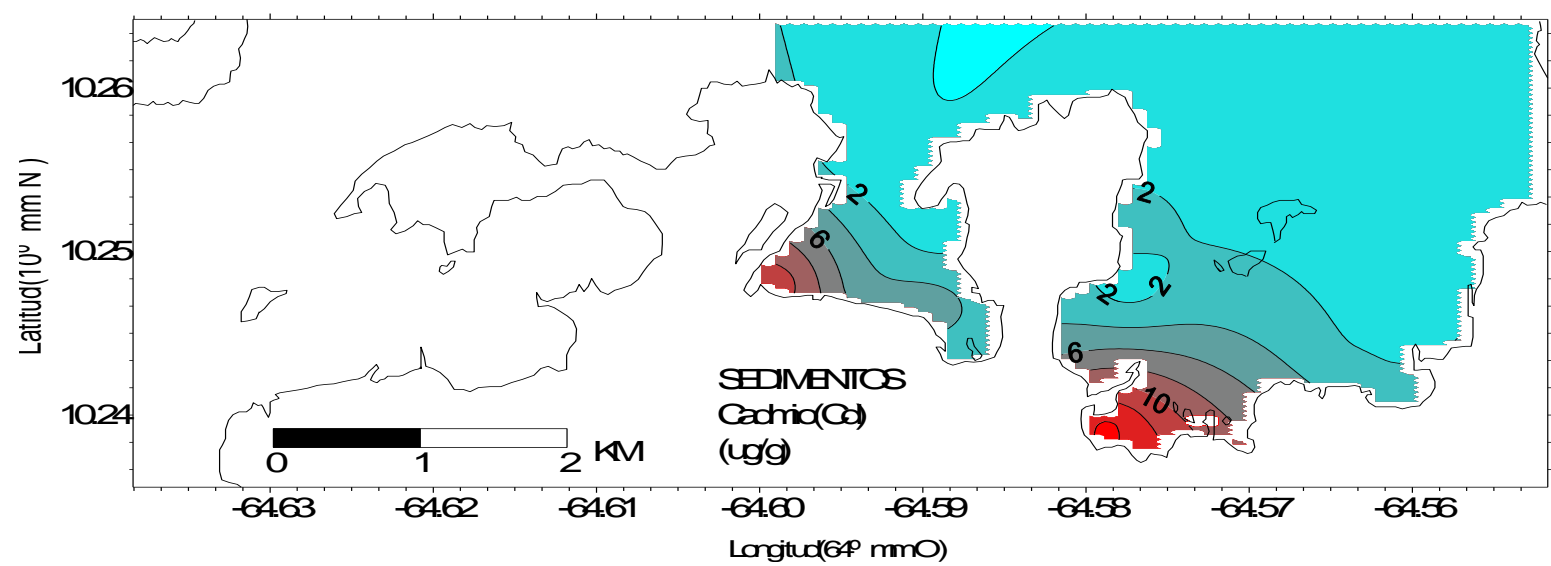

Figura 28.- Distribución espacial de las concentraciones de cadmio $(\mu \mathrm{g} / \mathrm{g})$ encontradas en los sedimentos superficiales del sector Guanta-Pertigalete, 11 Marzo de 1999.

\section{Cobre}

Las concentraciones de cobre en los sedimentos superficiales de las bahías de Guanta y Pertigalete estuvieron comprendidas entre 5,26 $\mu \mathrm{g} / \mathrm{g}$ y 43,19 $\mu \mathrm{g} / \mathrm{g}$, con un valor promedio de 19,20 $\mu \mathrm{g} / \mathrm{g}$. La desviación estándar de 12,76 es indicativa de la gran variabilidad de las concentraciones de este elemento (fig. 29). Las máximas concentraciones de cobre se ubicaron en el sector sur de ambas bahías, disminuyendo las concentraciones a medida que nos alejamos de los centros poblados y de la actividad industrial y portuaria. Esta distribución del cobre sugiere que el origen de este elemento en los sedimentos superficiales de los ecosistemas es debido a las actividades de origen antropogénico que allí se desarrollan. 


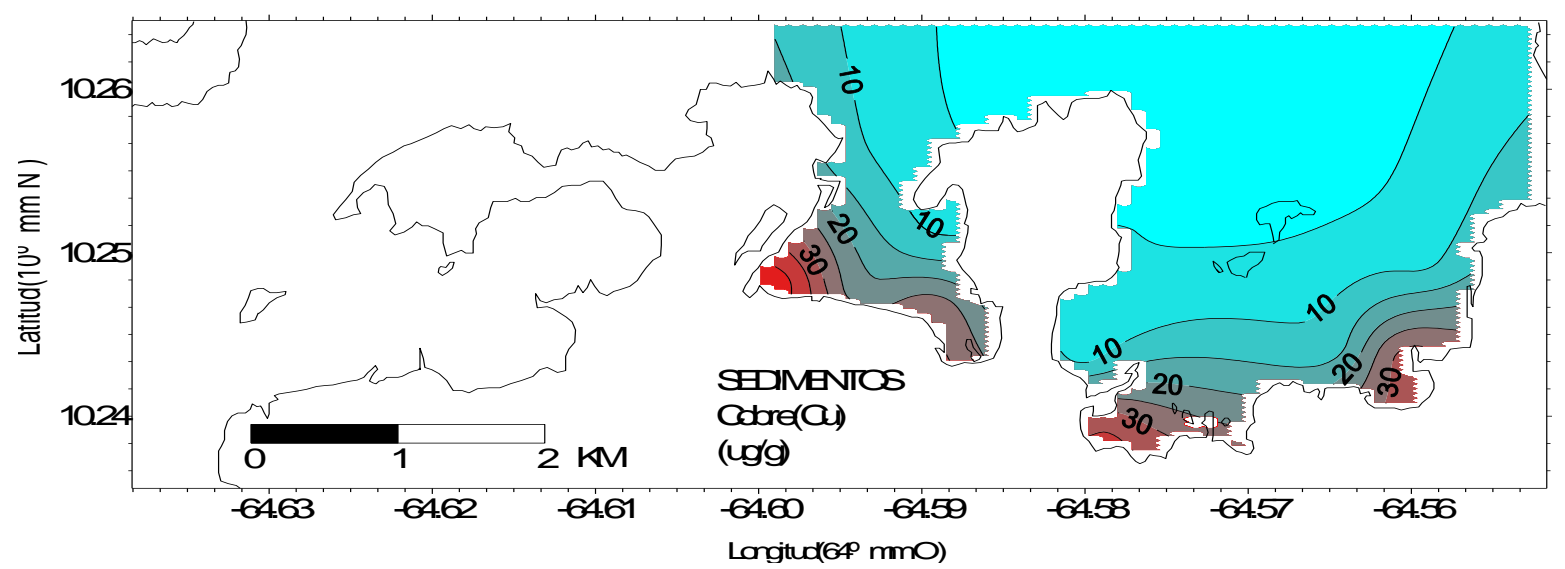

Figura 29- Distribución espacial de las concentraciones de cobre $(\mu \mathrm{g} / \mathrm{g})$ encontradas en los sedimentos superficiales del sector Guanta-Pertigalete, 11 Marzo de 1999.

\section{Cromo}

La distribución del cromo, en los sedimentos superficiales de las bahías de Guanta y pertigalete es presentada en la figura 30. Las concentraciones determinadas estuvieron comprendidas entre 12,61 y $179,42 \mu \mathrm{g} / \mathrm{g}$. Al igual que en el caso anterior, la desviación estándar de 66,14, existe una gran variabilidad de las concentraciones de este elemento. Los valores máximos de cromo se registraron hacia el sector sur de Guanta y hacia el sur-oeste de Pertigalete, zonas donde la actividad humana es más importante que la industrial, lo cual sugiere que son los desechos urbanos la principal fuente de este elemento al ecosistema.

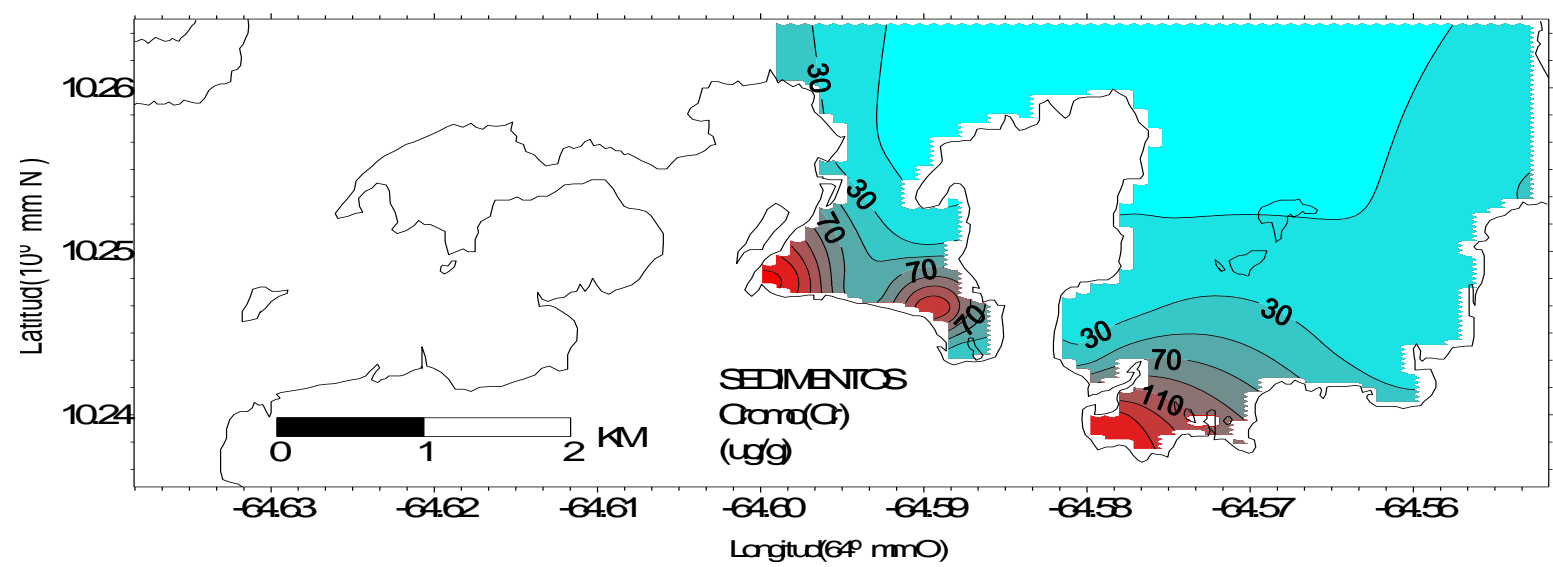

Figura 30.- Distribución espacial de las concentraciones de cromo $(\mu \mathrm{g} / \mathrm{g})$ encontradas en los sedimentos superficiales del sector Guanta-Pertigalete, 11 Marzo de 1999. 


\section{Hierro}

Las concentraciones de hierro estuvieron comprendidas entre 4.291 y $31.918 \mu \mathrm{g} / \mathrm{g}$ (Figura 31); existe un incremento marcado de las concentraciones en el sector donde funciona la planta de cementos, abarcando toda el área oriental de la bahía de Pertigalete. Esta distribución sugiere que las actividades allí realizada son la principal fuente de este elemento al ecosistema. Un incremento de las concentraciones fue igualmente detectado en el sector sur de la bahía de Guanta, aunque de menor intensidad al de Pertigalete. Los desechos urbanos, así como la actividad portuaria en la región contribuyen a este incremento de las concentraciones de hierro en los sedimentos superficiales de la bahía.

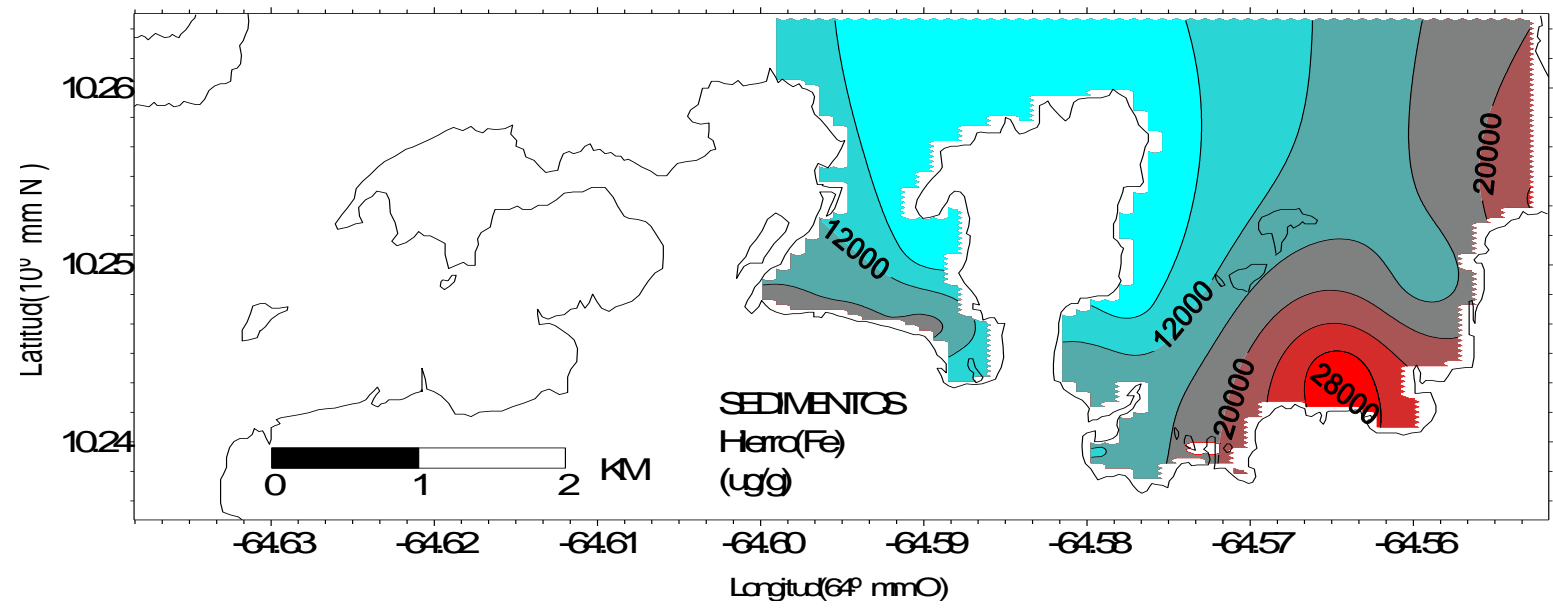

Figura 31.- Distribución espacial de las concentraciones de hierro $(\mu \mathrm{g} / \mathrm{g})$ encontradas en los sedimentos superficiales del sector Guanta-Pertigalete, 11 Marzo de 1999.

\section{Manganeso}

El manganeso (Figura 32) presentó una distribución muy diferente a la del resto de los metales examinados. Las concentraciones de este elemento estuvieron comprendidas entre $4,67 \mu \mathrm{g} / \mathrm{g}$ y 384,63 $\mu \mathrm{g} / \mathrm{g}$, con un valor promedio de 76,66 $\mu \mathrm{g} / \mathrm{g}$ y una desviación estándar de 107,51. Los valores máximos detectados se ubicaron hacia el sector norte de las bahías, con bajas concentraciones hacia el interior de las mismas. Esta distribución es bastante difícil de describir, haciéndose necesario una investigación más cerrada para la detección de las fuentes de este elemento en el área. 


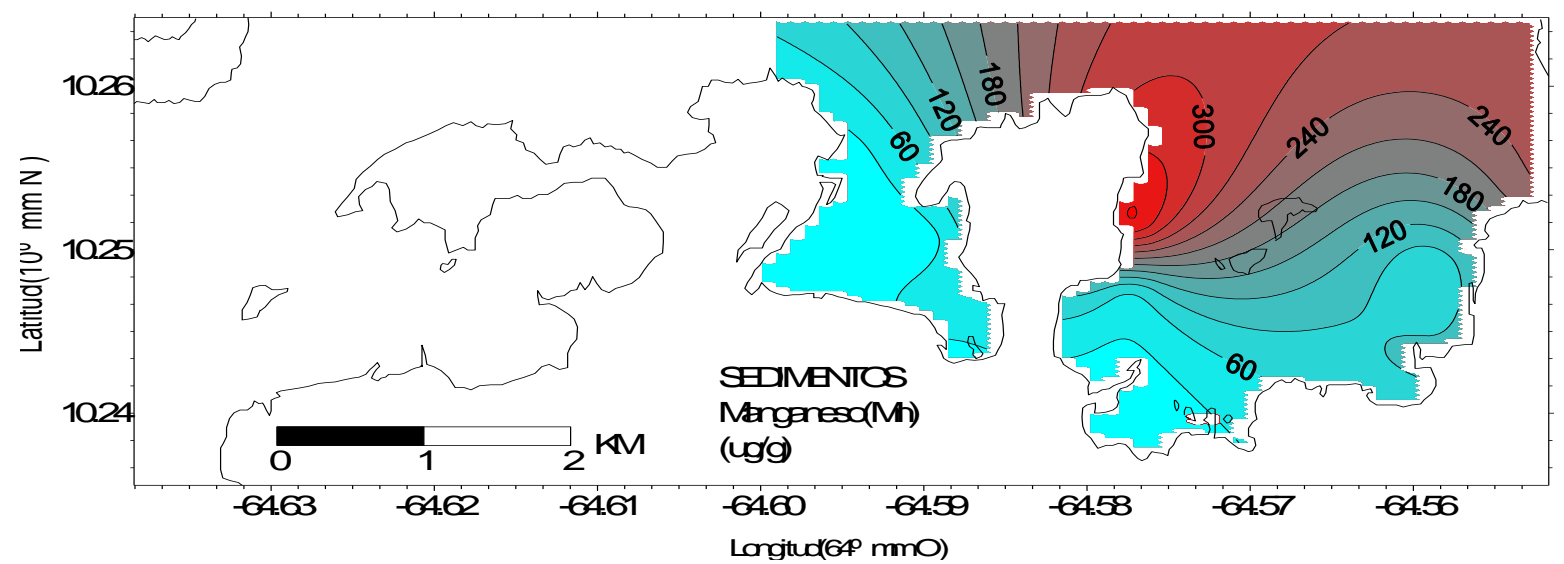

Figura 32.- Distribución espacial de las concentraciones de manganeso $(\mu \mathrm{g} / \mathrm{g})$ encontradas en los sedimentos superficiales del sector Guanta-Pertigalete, 11 Marzo de 1999

Níquel

Las concentraciones de níquel, en los sedimentos superficiales, estuvieron comprendidas entre 9,32 y $92,05 \mu \mathrm{g} / \mathrm{g}$, con un valor promedio de 29,53 $\mu \mathrm{g} / \mathrm{g}$ y una desviación estándar de 22,71 (fig. 33). Las máximas concentraciones se ubicaron hacia los sectores sur-occidentales de ambas bahías, sugiriendo que su principal fuente de llegada al ecosistema lo constituye las aguas domésticas vertidas. Las concentraciones disminuyen gradualmente hacia el norte de los ecosistemas, donde se detectaron los valores mínimos del metal.

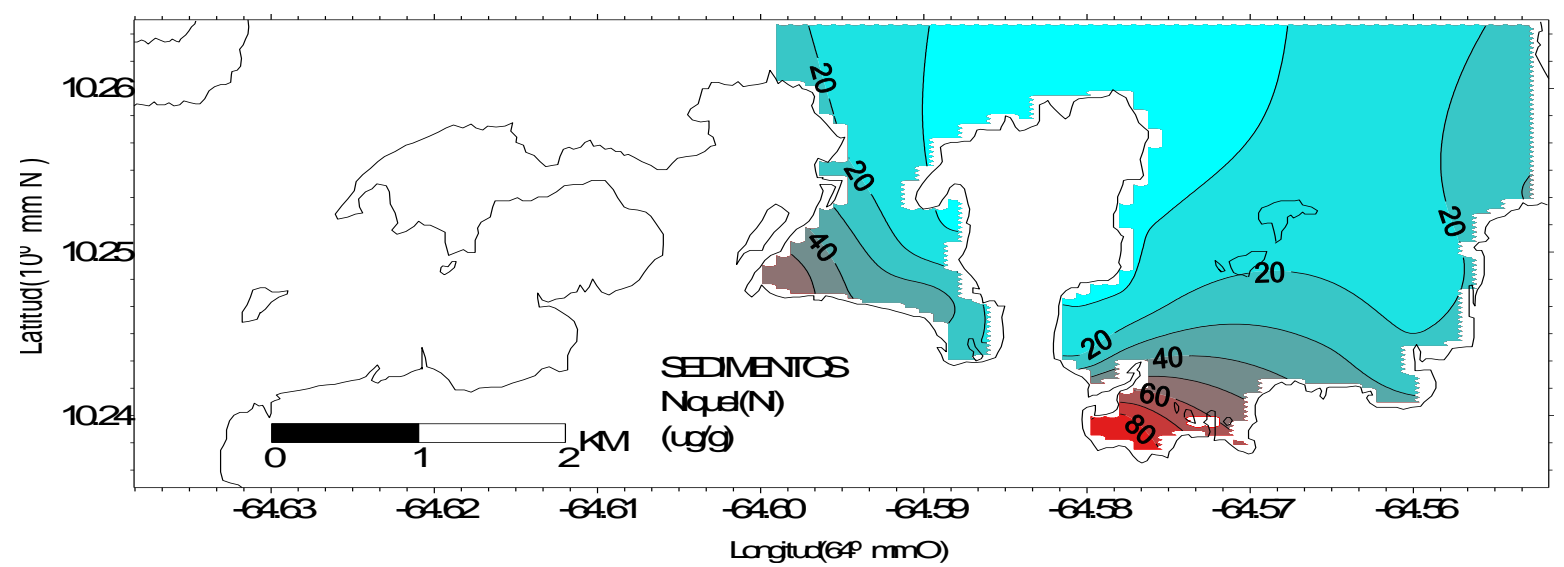

Figura 33.- Distribución espacial de las concentraciones de níquel $(\mu \mathrm{g} / \mathrm{g})$ encontradas en los sedimentos superficiales del sector Guanta-Pertigalete, 11 Marzo de 1999

Cinc

La distribución de cinc en los sedimentos superficiales de las bahías de Guanta y Pertigalete es presentada en la figura 34. Las concentraciones detectadas estuvieron comprendidas entre 54,06 y $501,34 \mu \mathrm{g} / \mathrm{g}$, con un valor promedio de 225,60 $\mu \mathrm{g} / \mathrm{g}$ y una desviación esttándar de 146,99. Las más 
elevadas concentraciones de este elemento se ubicaron hacia el sector sur de ambas bahías. Un incremento de las concentraciones es observado en las cercanías de la planta de cementos, lo cual sugiere que existe un aporte de este elemento por las actividades allí desarrolladas. De manera general, se puede decir que el principal aporte de este elemento a los ecosistemas examinados lo constituyen las aguas servidas, vertidas en la zona costera sin ningún tipo de tratamiento previo.

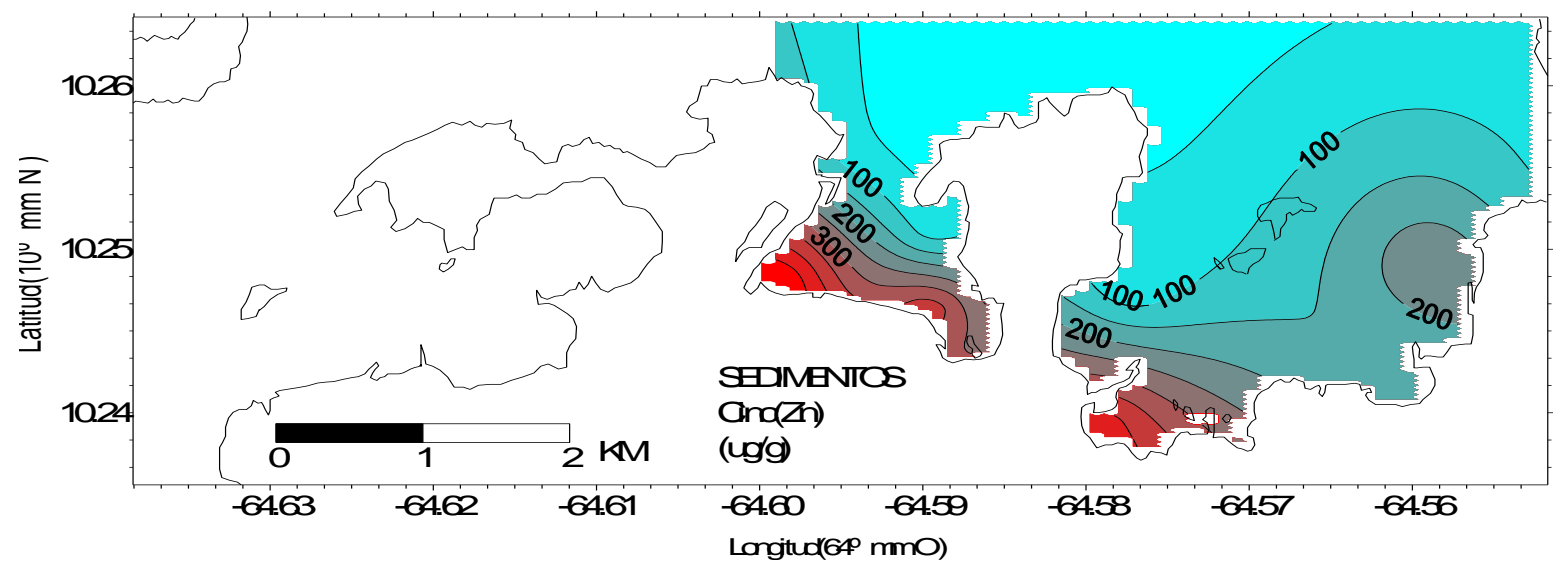

Figura 34.- Distribución espacial de las concentraciones de cinc $(\mu \mathrm{g} / \mathrm{g})$ encontradas en los sedimentos superficiales del sector Guanta-Pertigalete, 11 Marzo de 1999.

\section{Plomo}

La distribución del contenido de plomo en los sedimentos superficiales de las bahías de Guanta y Pertigalete es presentada en la figura 35. Las concentraciones de este elemento estuvieron comprendidas entre 7,92 y $27,53 \mu \mathrm{g} / \mathrm{g}$, con un valor promedio de $15,51 \mu \mathrm{g} / \mathrm{g}$ y una desviación estándar de 6,98. Los valores máximos de plomo se detectaron hacia el sector sur de los ecosistemas examinados, con mayor énfasis en los sectores sur-oeste y sur-este de Guanta y en el sur-oeste de pertigalete. Esta distribución sugiere que una de las principales fuentes de este elemento en los ecosistemas lo constituye el vertido de los desechos urbanos en la región. Sin embargo, hay que resaltar la importancia del tráfico marítimo en la bahía de Guanta, así como en el sector de Pamatacualito, lo cual debe estar ejerciendo una fuerte presión sobre la distribución de este elemento. 


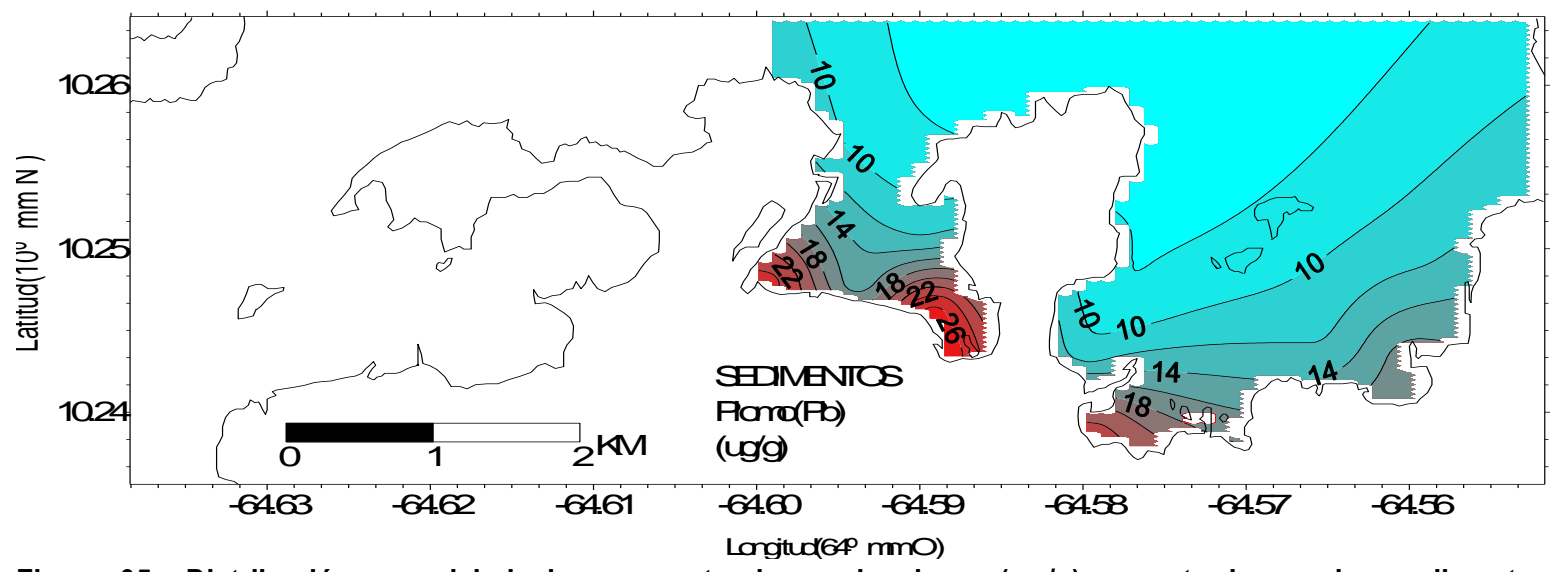

Figura 35.- Distribución espacial de las concentraciones de plomo $(\mu \mathrm{g} / \mathrm{g})$ encontradas en los sedimentos superficiales del sector Guanta-Pertigalete, 11 Marzo de 1999

\section{PROBLEMÁTICA AMBIENTAL DE LAS BAHIAS DE GUANTA Y PERTIGALETE.}

De los resultados presentados se evidencia la existencia de un deterioro ambiental de ambas bahías. Uno de los problemas más agudos lo constituye el vertido de aguas negras sin tratamiento alguno, al ecosistema. La falta de colectores de las aguas usadas, unido a la utilización de los drenes de lluvia como vertederos de aguas negras y desechos sólidos, han creado un grave problema ambiental en la zona, particularmente en la bahía de Guanta. La secuencia de fotografías que se presenta a continuación muestra las condiciones ambientales de Guanta en la actualidad. Las descargas de aguas negras llegan a la bahía por diferentes vías, sin que exista un mínimo control sobre el cauce de las mismas. Los pobladores que habitan en la región se ven obligados a convivir con los permanentes olores desagradables y pestilentes que impregnan el ambiente, llegando los mismo a la acción de consumir organismos marinos capturados en el área, los cuales dado las condiciones del medio tendrán un elevado contenido de contaminantes. La falta de políticas por los Gobiernos Regionales han ocasionado un caos ambiental en este importante sector del estado Anzoátegui, donde los problemas de insalubridad son el factor dominante. 


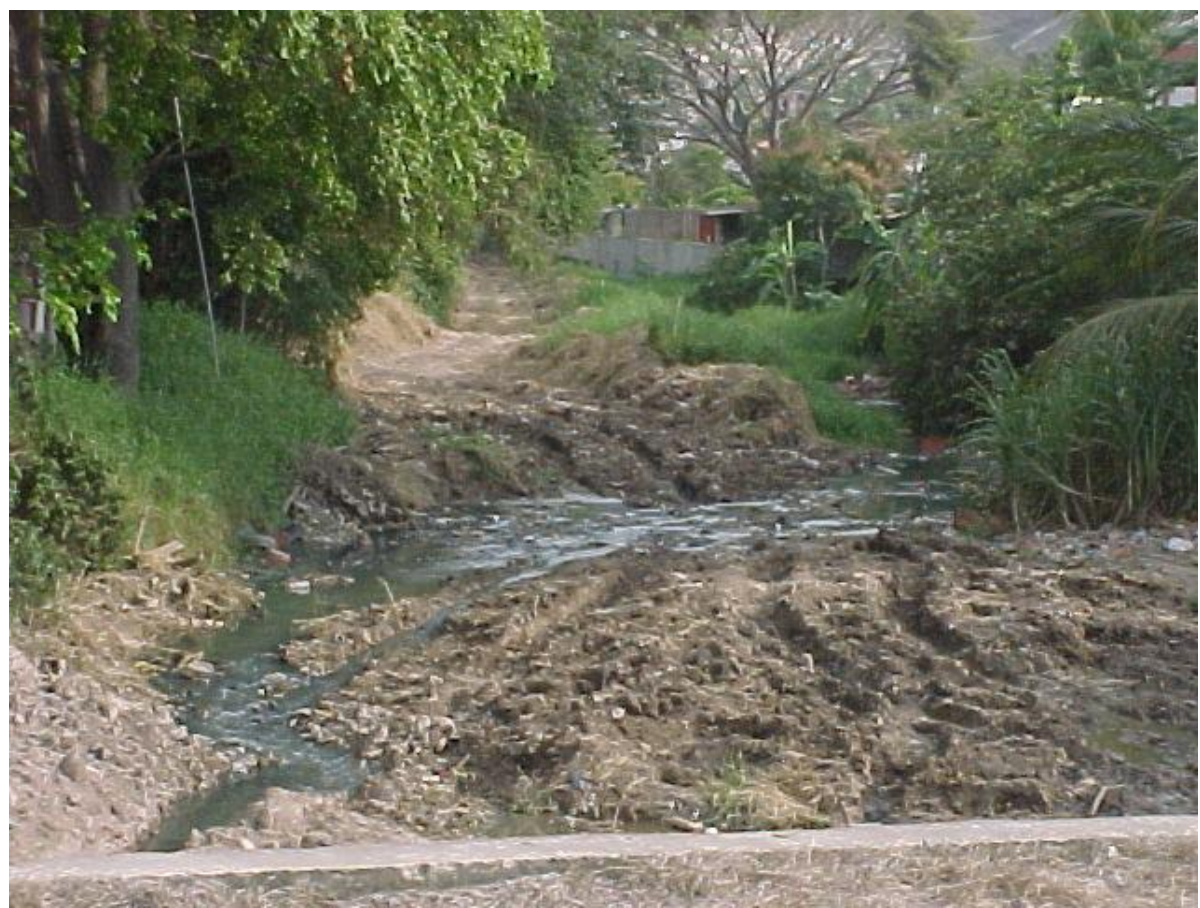

Foto 1.- Riachuelos de aguas negras en las adyacencias de la población de Guanta y que luego atraviesa la ciudad. En su ribera se aprecia la acumulación de desperdicios

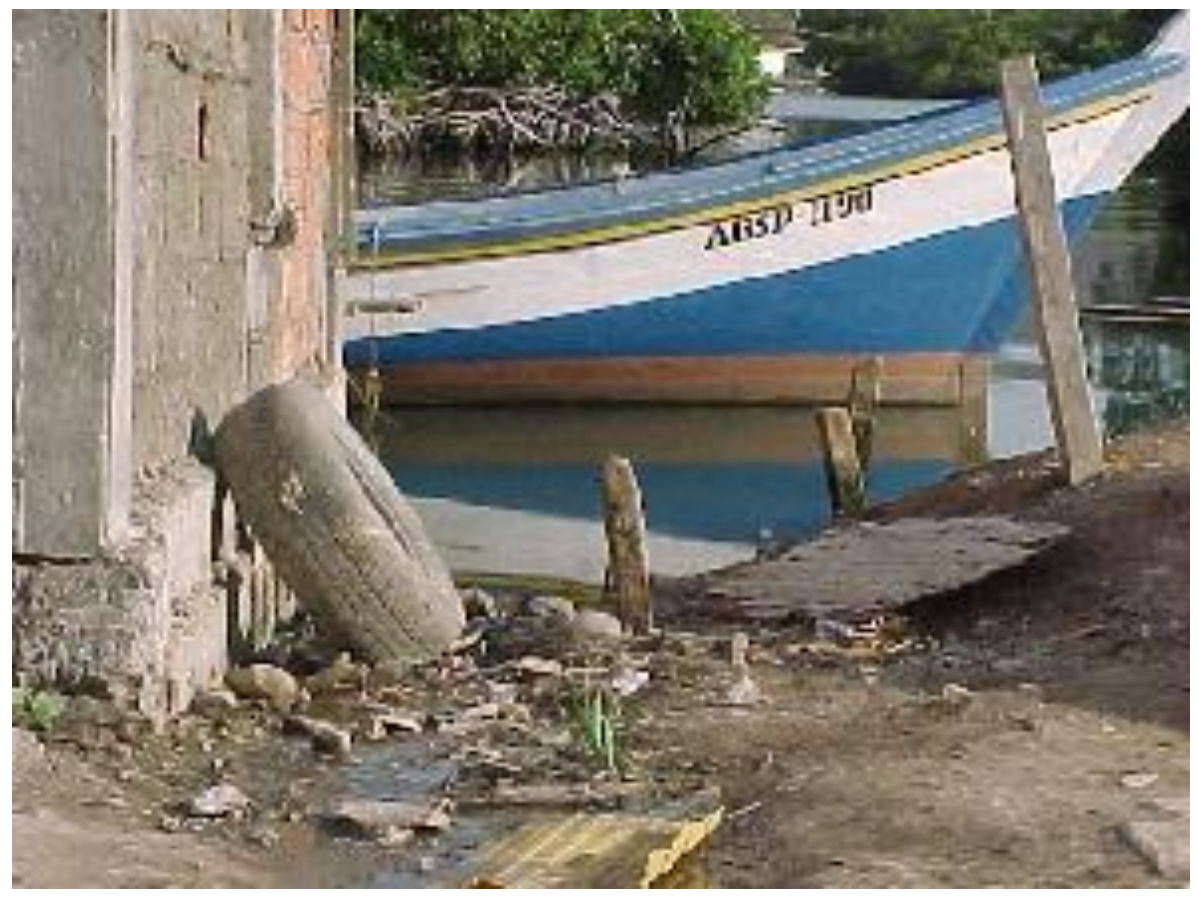

Foto 2.- Un acercamiento a uno de los pequeños muelles de pescadores dentro de la Bahía de Guanta. Se aprecia un pequeño desagua de uso doméstico que drena directamente a la bahía, así como de material remanente o desperdicios. 


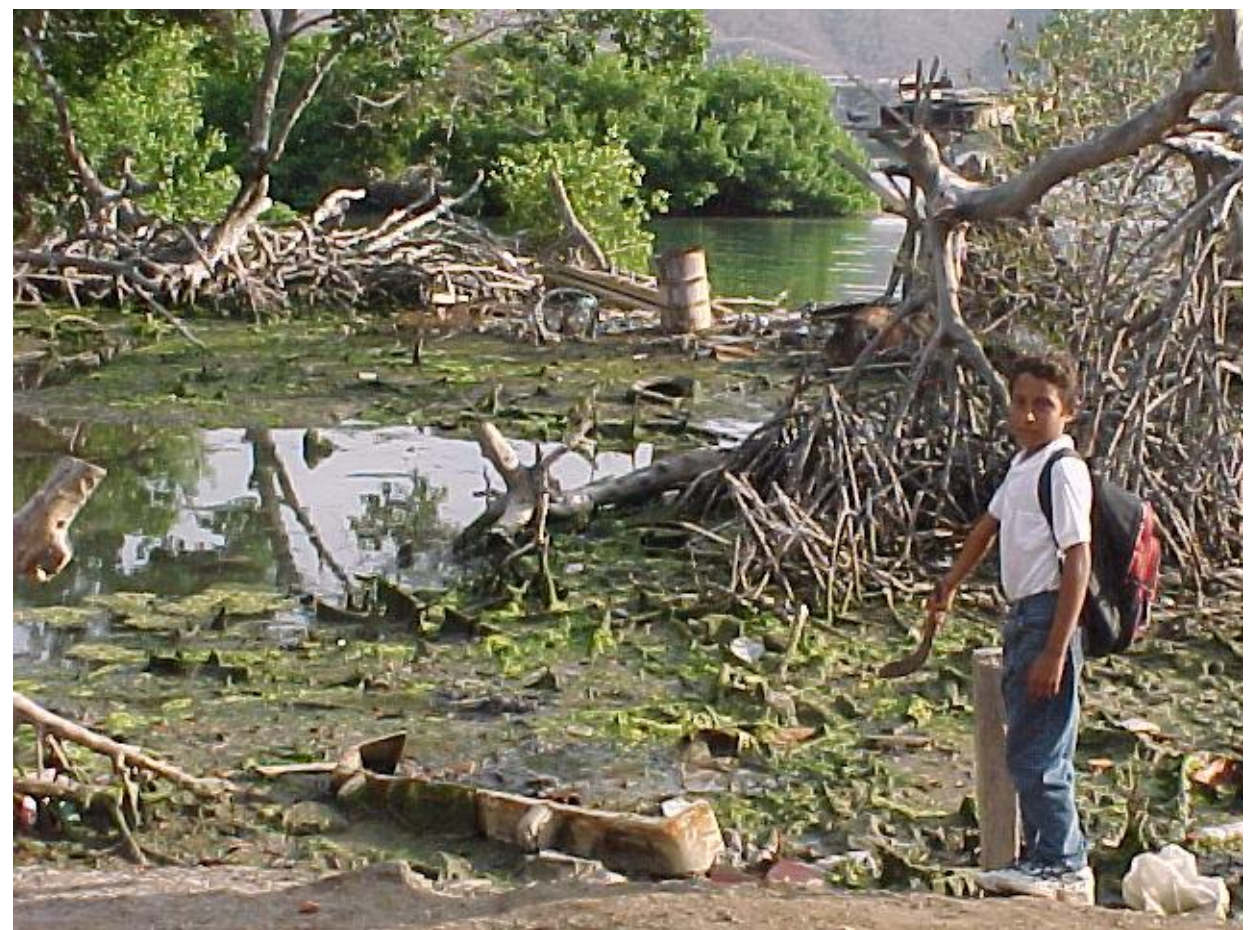

Foto 3.- Uno de los más graves problemas de la bahía de Guanta lo constituye el drenaje conocido como "Drenaje C", que transporta la mayor parte de las aguas negras de la ciudad de Puerto La Cruz, y que posteriormente son descargadas en el sector ilustrado en la fotografía. Esta descarga afecta considerablemente al ecosistema, tal como lo señalan los resultados arriba presentados.

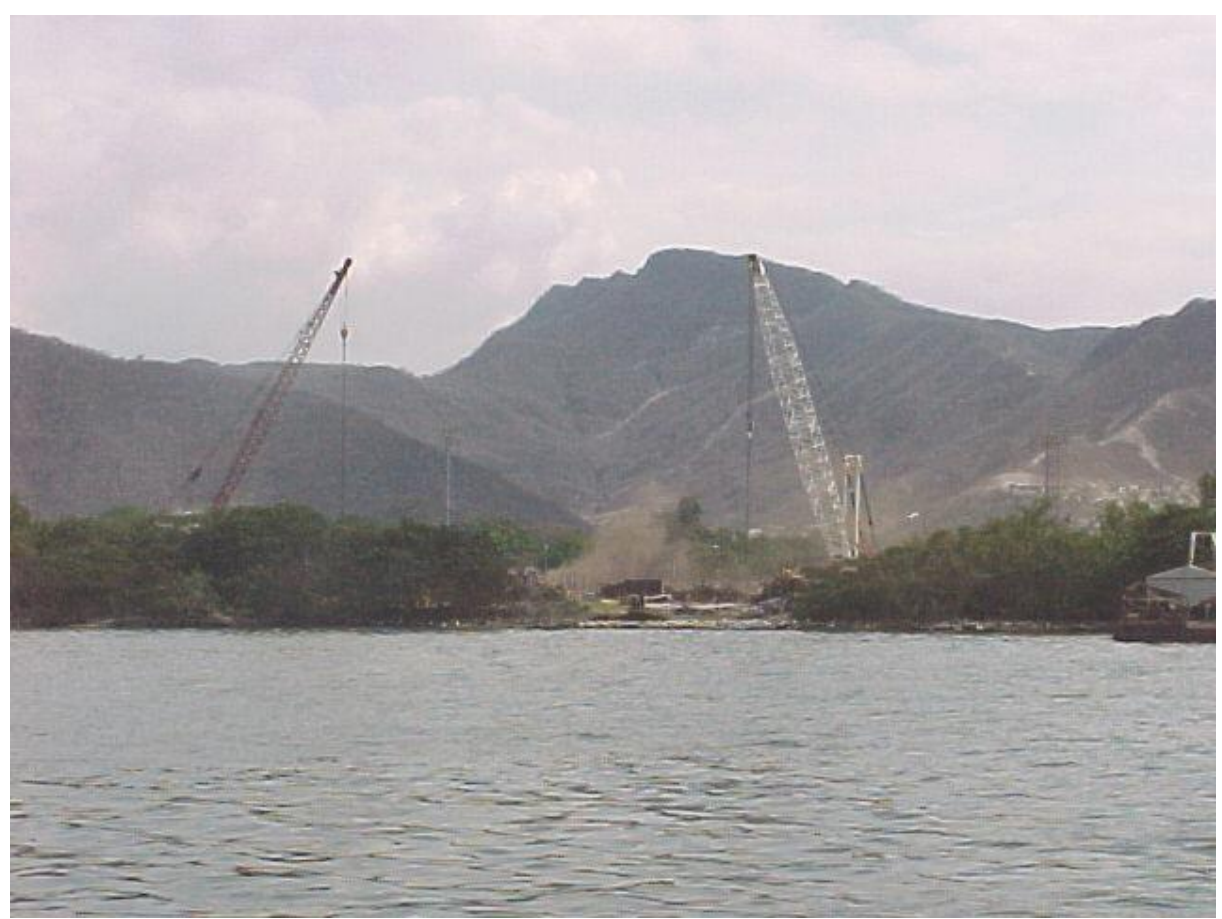

Foto 4.- Intensa actividad de la industria de la construcción en los alrededores de la bahía de Guanta.

Una gran porción de la población de Guanta está constituida por familias de muy bajos recursos económicos, en consecuencia habitan en las zonas próximas a la bahía. La falta de los servicios 
básicos indispensables obliga a que la deposición de los excrementos y otros desechos se viertan directamente al ecosistema. En la secuencia de fotos siguiente se puede apreciar las innumerables letrinas construidas. Unas sobre el litoral a pocos metros de la línea de playa y otras dentro del manglar, mostrando de esta manera el progresivo deterioro de la calidad de las aguas y sedimentos locales. En particular, hacia la zona conocida como Volcadero. De igual manera, el vertido de todo tipo de desechos sólidos ocasiona un impresionante y desagradable espectáculo paisajístico al visitante. La mayoría de estos desechos son de látex (bolsas plásticas, neumáticos) y de herrumbre (partes de autos desechadas). Todo ello dado la lentitud en que el medio acuático natural puede degradar esos desperdicios inducen una permanente contaminación de las aguas, efectos que luego se transfiere a la flora ribereña (manglares) y a la fauna acuática (peces, bivalvos y especies autóctonas de a región).

Creemos que la solución a esta problemática no puede circunscribirse al sólo hecho de construir y poner en funcionamiento la planta de tratamiento (actualmente en proceso de construcción, foto 4), ya que no existen planes o proyectos para canalizar la red aguas negras de toda la región hacia la planta. Se ha informado a la opinión pública que en un principio, se tiene previsto la aducción, a la planta, de aquellas urbanizaciones y/o barriadas que disponen en la actualidad de un sistema de alcantarillado, siendo esto una solución a medias de la problemática ambiental de Guanta.

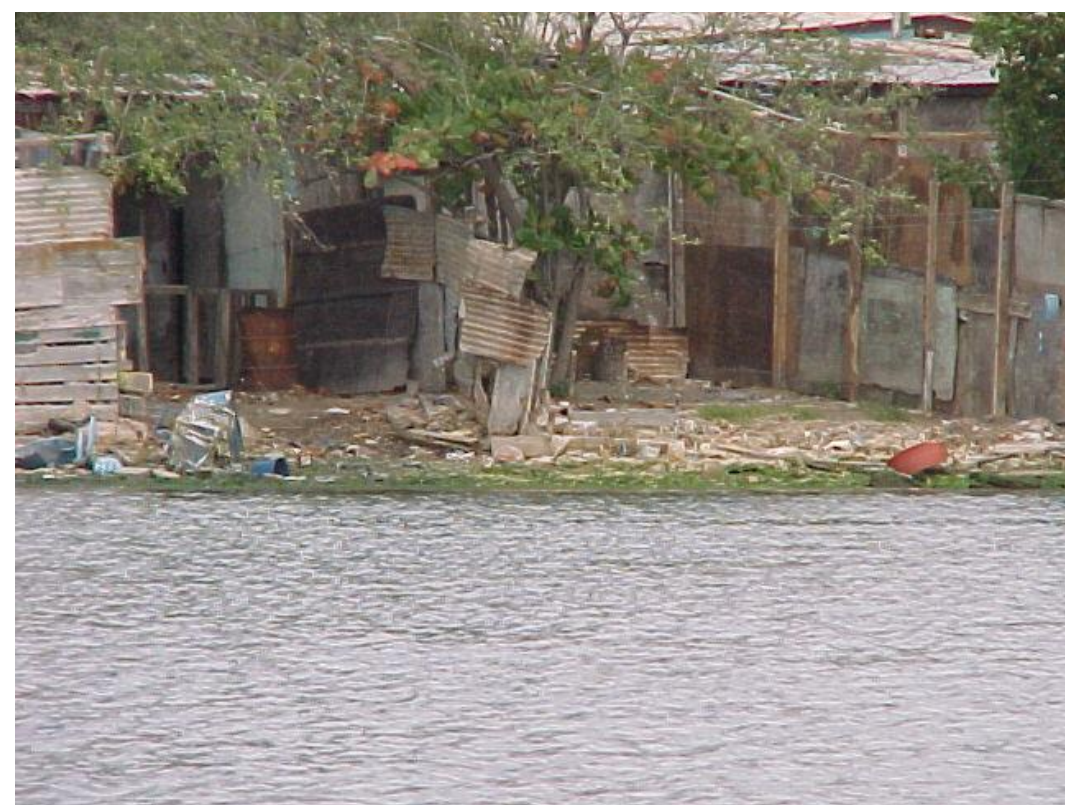

Foto 5. Patio de una vivienda de pescadores en la zona de Volcadero. 


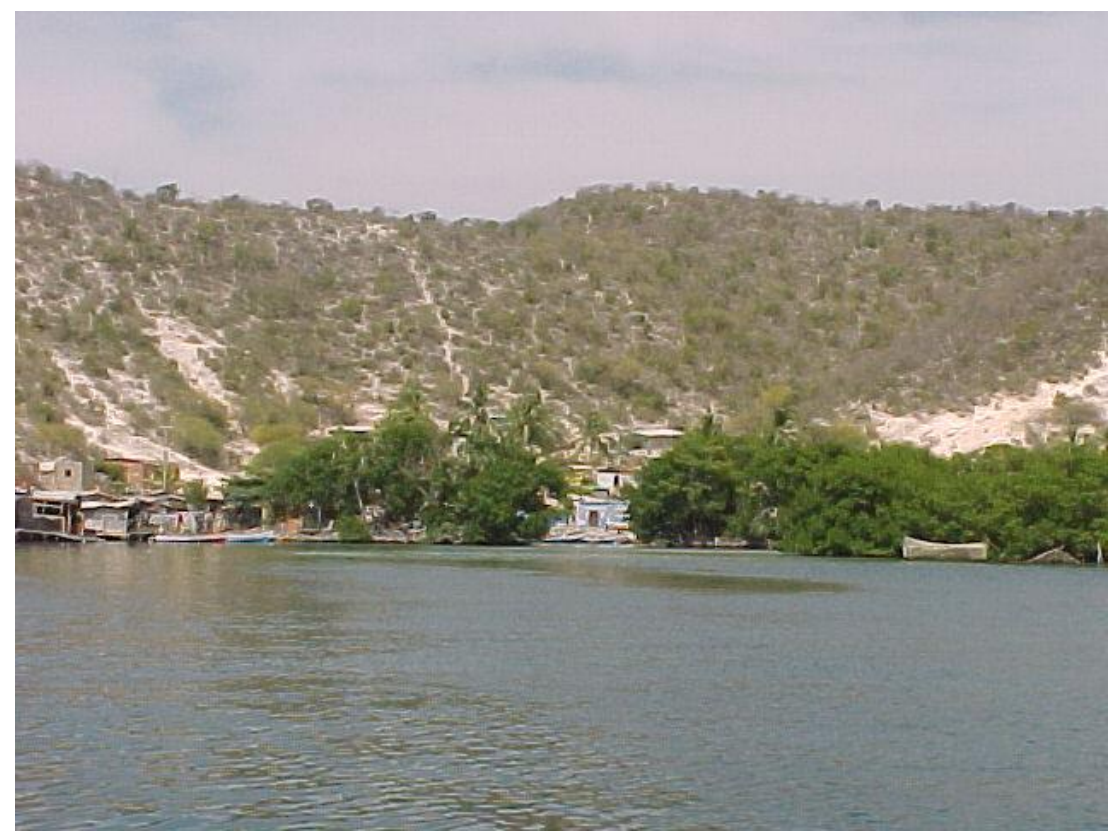

Foto 6.- Invasión del manglar. Los pobladores construyen dentro del área del bosque del manglar.

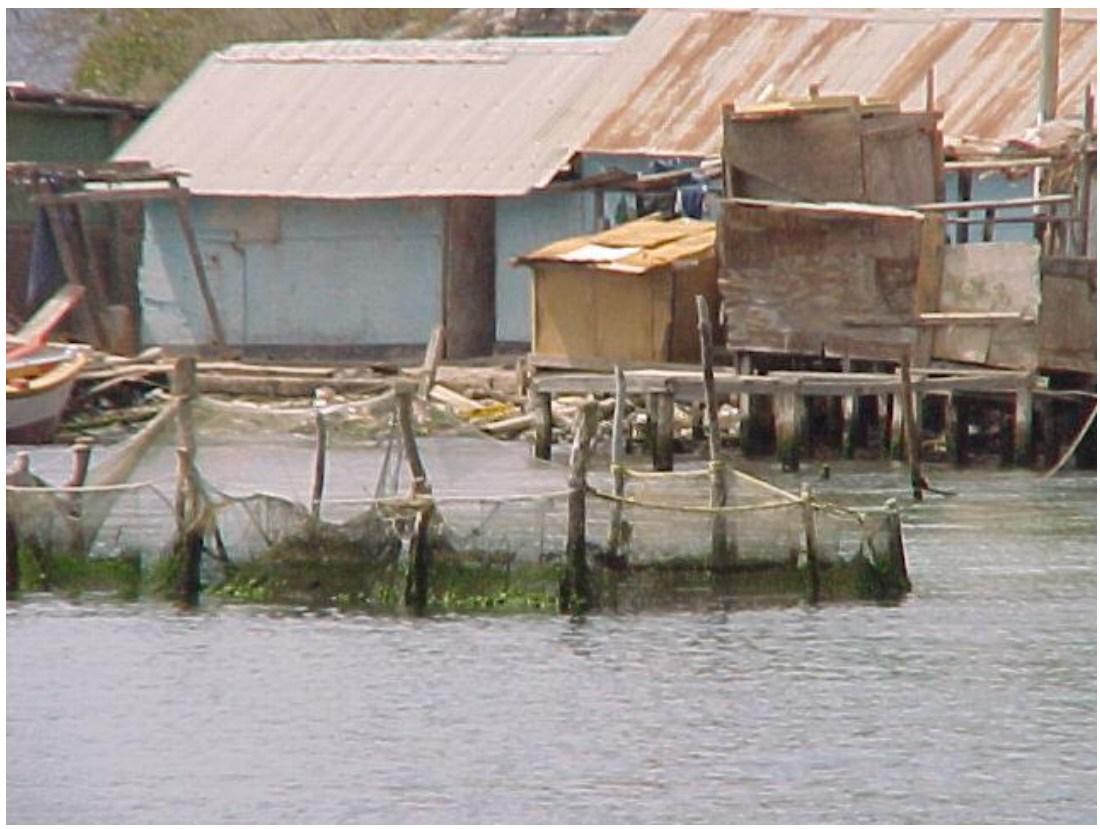

Foto 7.- Al fondo letrinas o escusados y al frente un aparejo de pesca. 


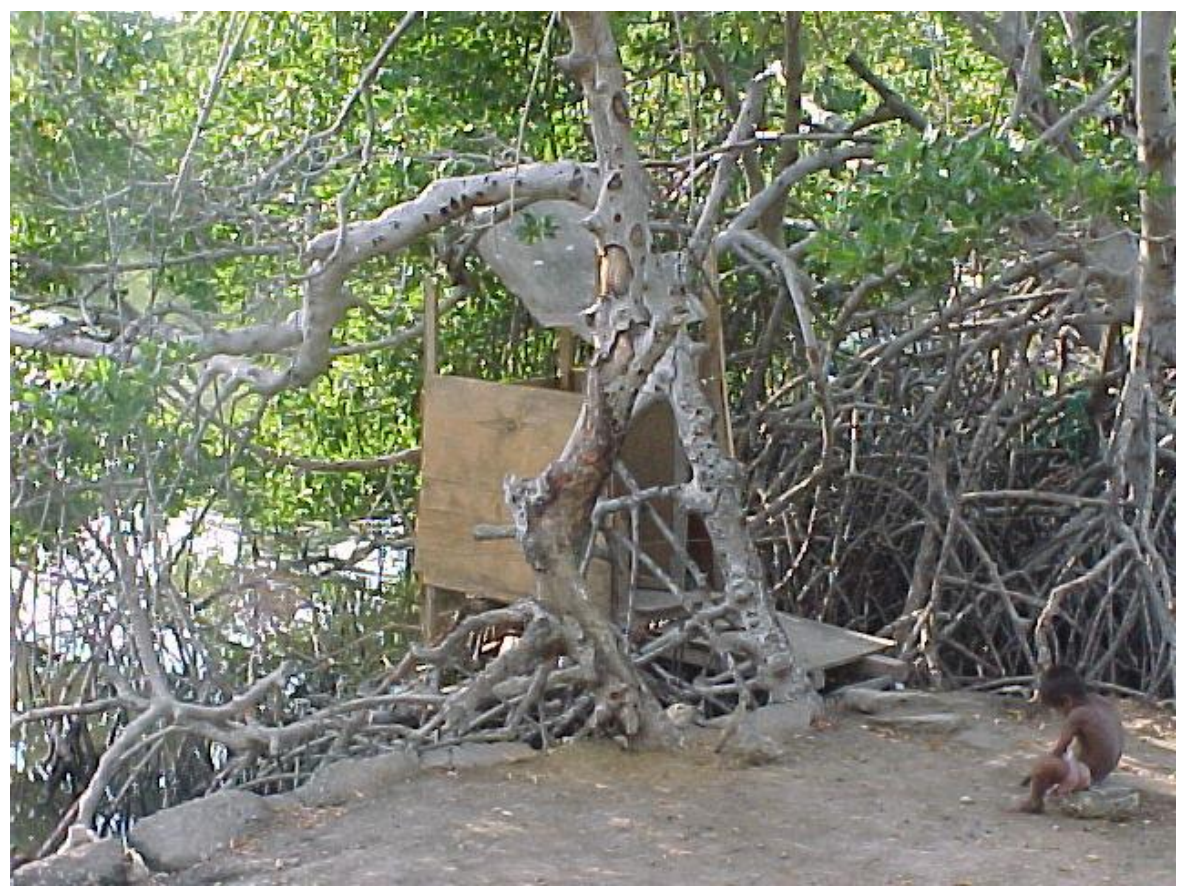

Foto 8.- Una letrina construida dentro de las raíces aéreas del mangle, al fondo la Bahía de Guanta.

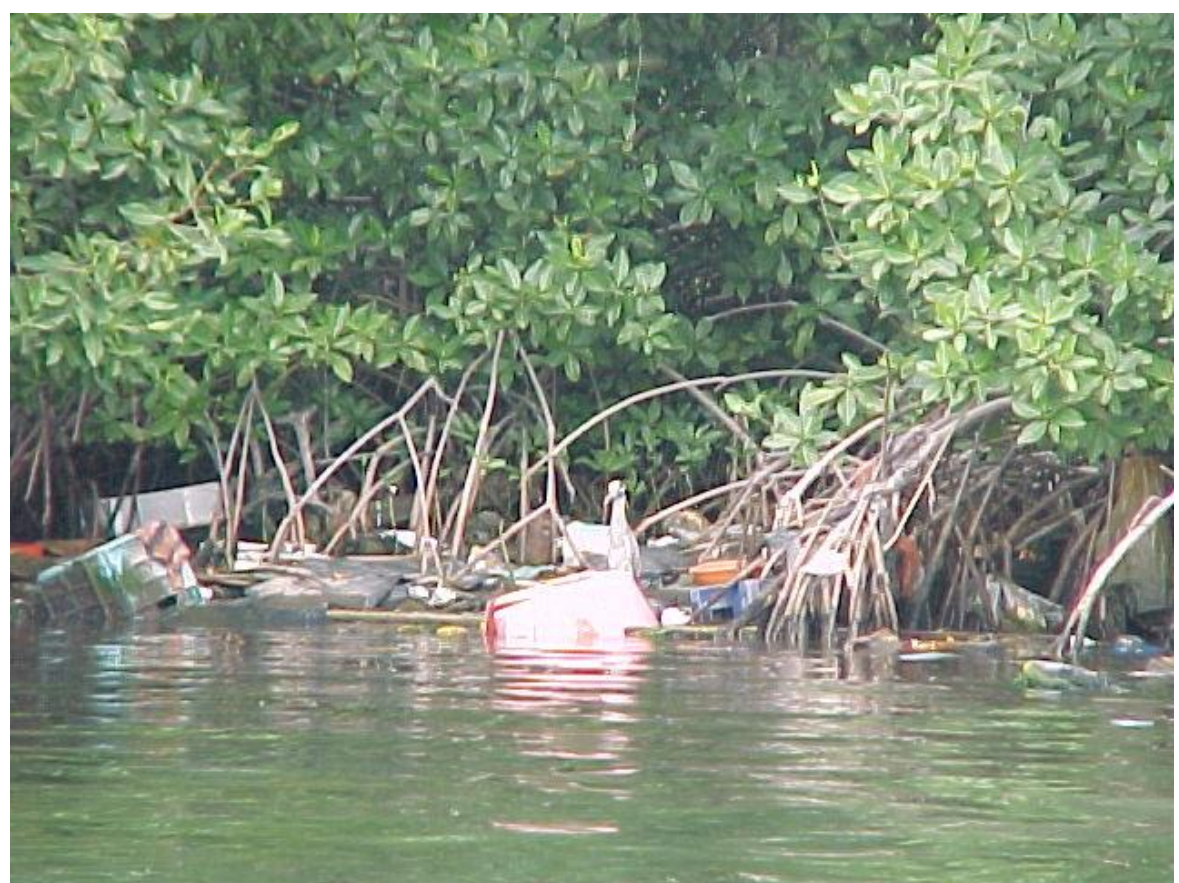

Foto 9.- Innumerables objetos de diversos materiales tienen su destino final en las márgenes de la bahía de Guanta. 


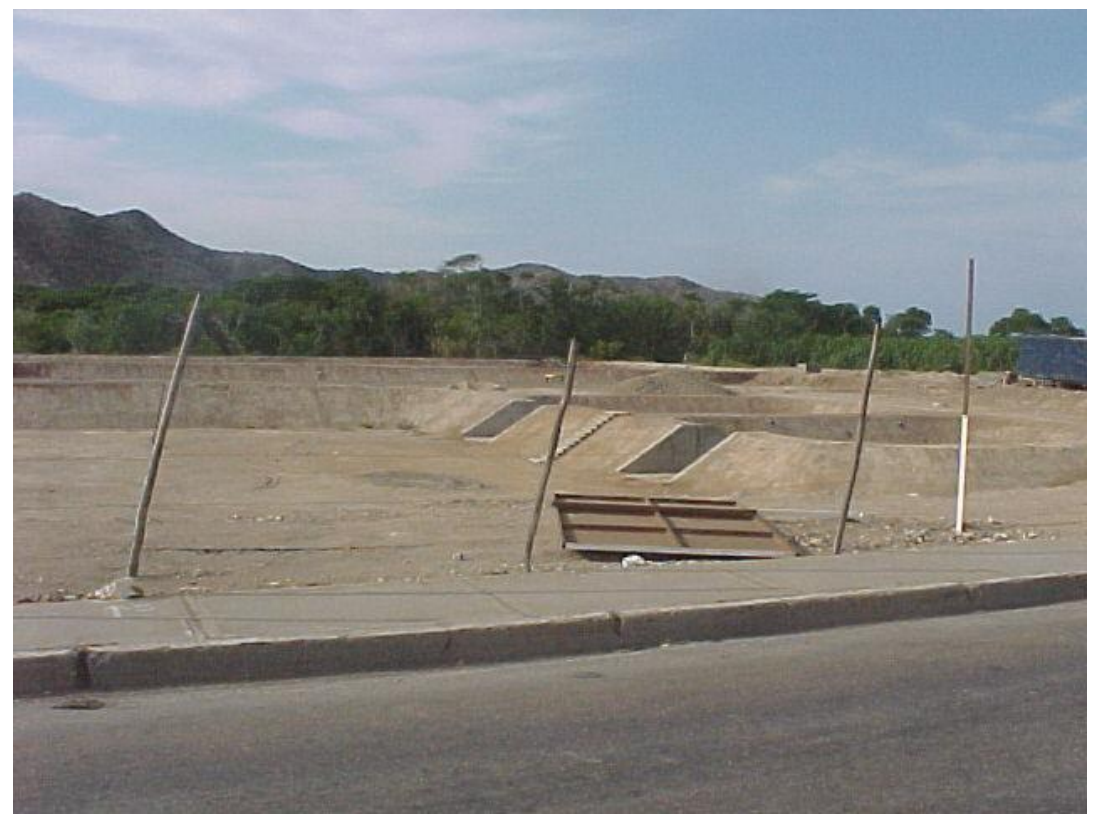

Foto 10.- Piscinas o tanques de la nueva Planta de Tratamiento en proceso de construcción en la vecindad de la bahía de Guanta.

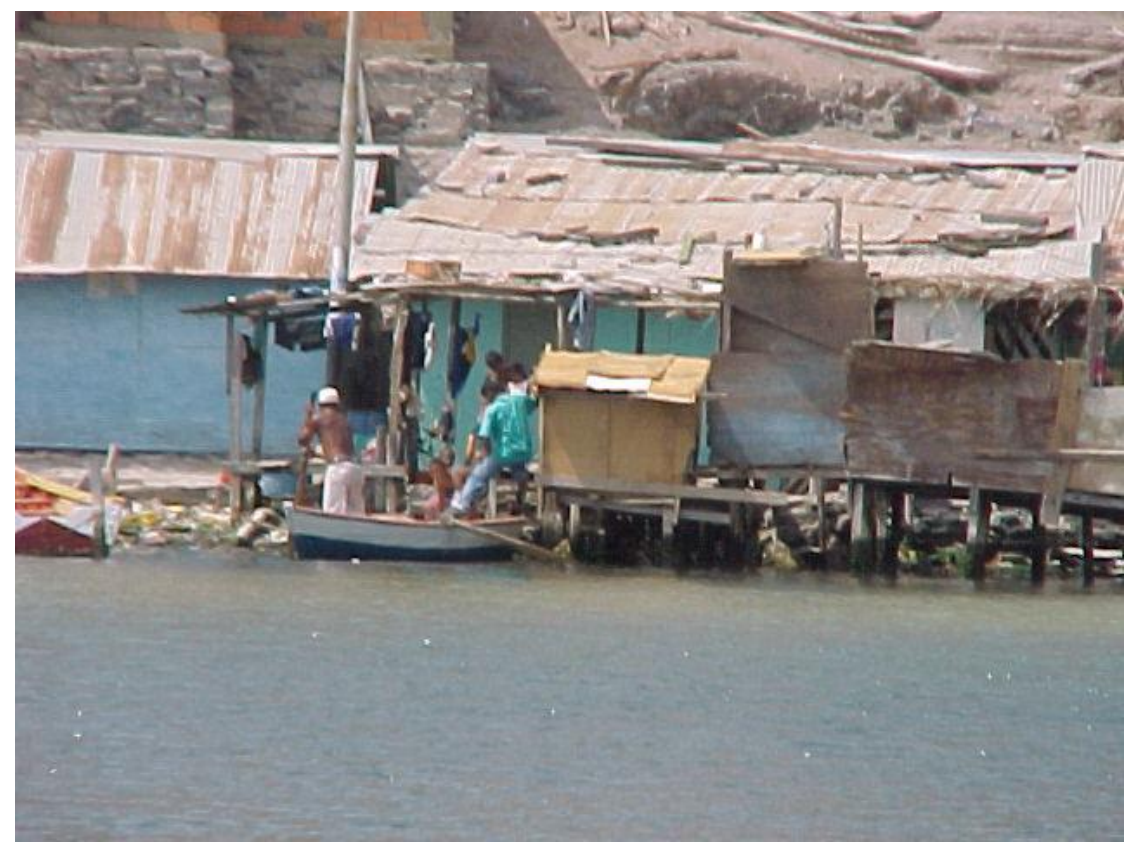

Foto 11.- El intenso estrés a que se ve sometido el ecosistema por las variadas actividades de sus pobladores Otro de los graves problemas existente en Guanta lo constituye las operaciones portuarias. Guanta es el principal puerto de la región oriental del país, con un movimiento portuario bastante elevado. Es evidente que el tráfico de embarcaciones en la zona contribuye al deterioro ambiental de la bahía, ya que no existen suficientes mecanismos de control del vertido de desechos hacia el medio marino. 


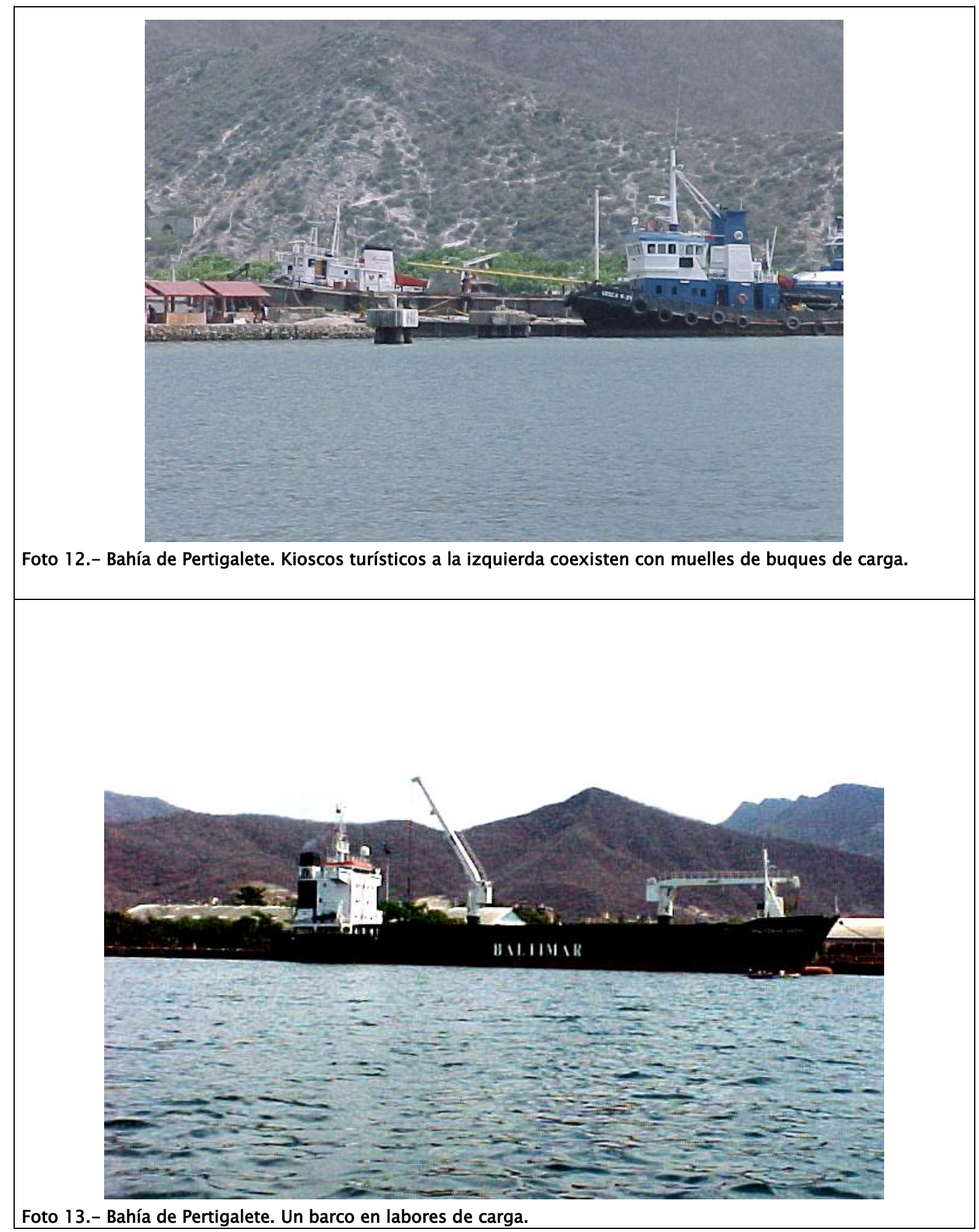




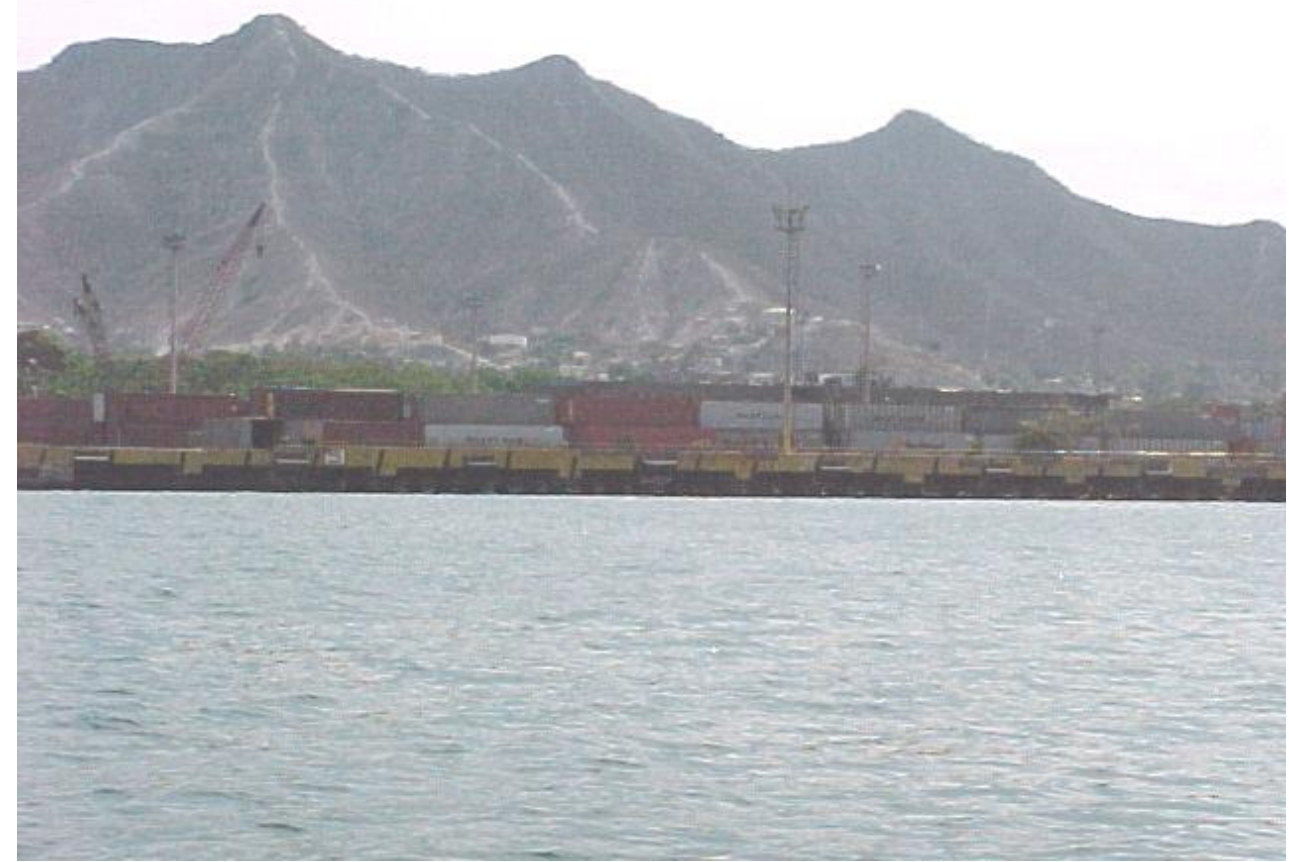

Foto 14.- Muelles de carga y al fondo sección de la empresa Vencemos. Bahía de Pertigalete.

Por último, el abandono de embarcaciones en la zona crea otro grave problema. La corrosión de estas embarcaciones son una fuente potencial de metales, tanto a las aguas como a los sedimentos.

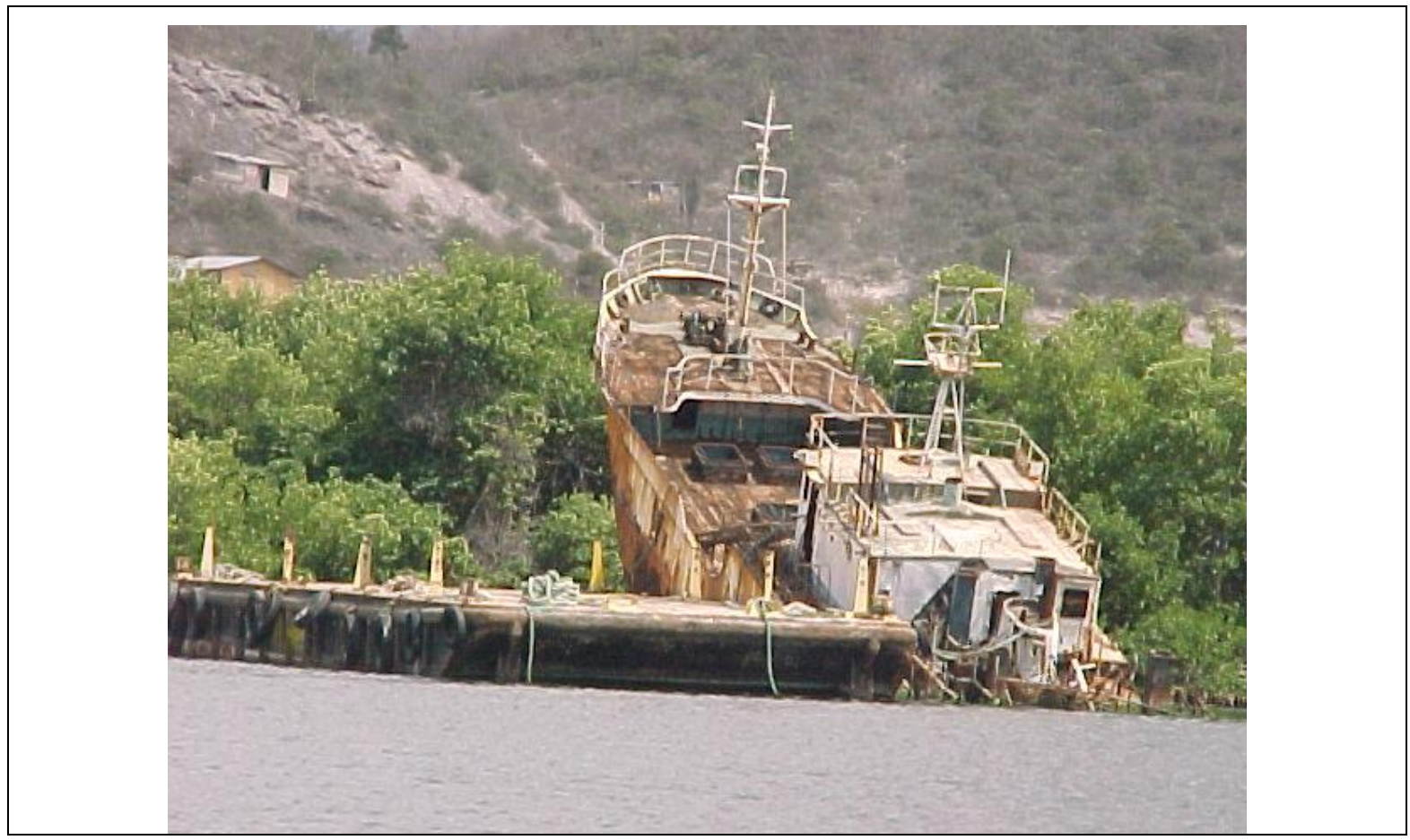


Foto 15.-. Bahía de Guanta. Cementerio de Barcos.

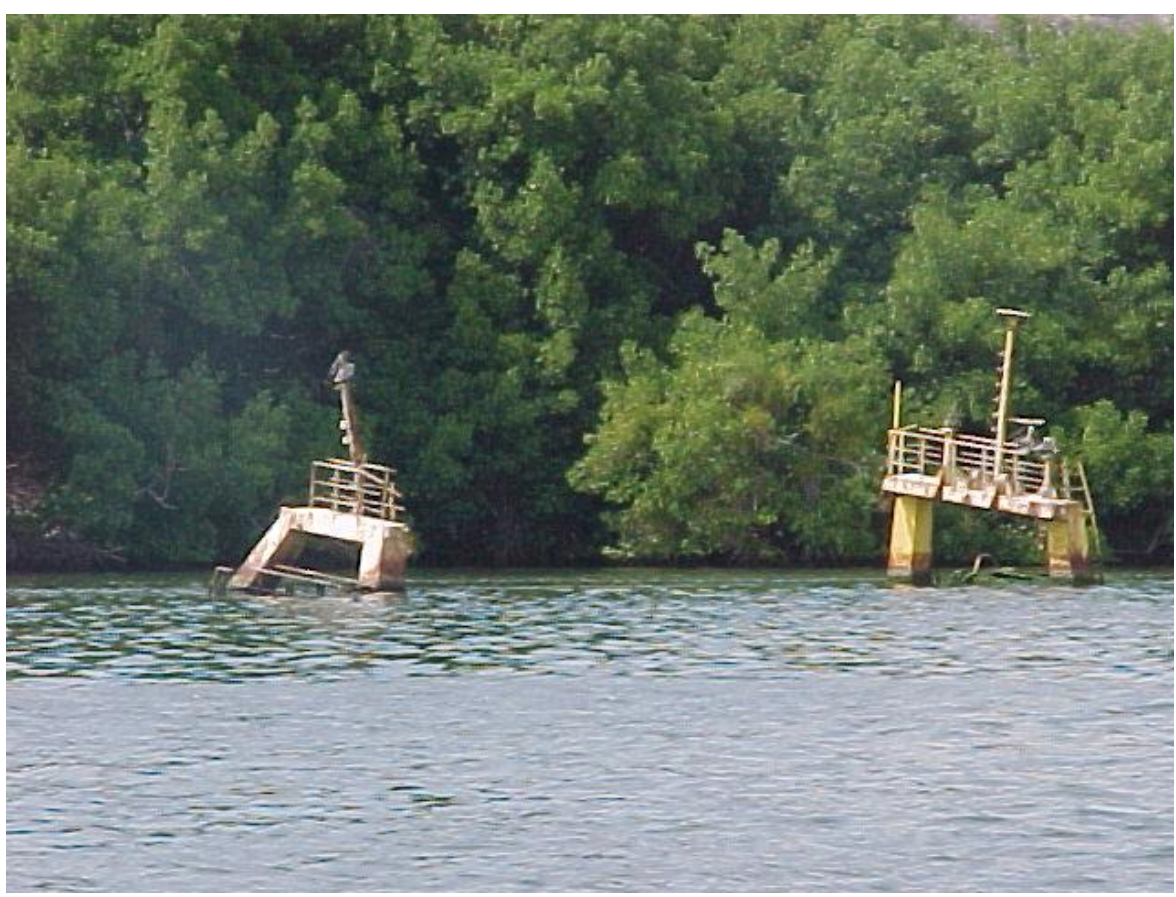

Foto 16.- bahía de Guanta. Cementerio de barcos. Al fondo el exuberante manglar sirve de testigo.

La principal problemática en Pertigalete lo constituye la planta de cementos Vencemos. Se puede apreciar la liberación de grandes cantidades de partículas a la atmósfera durante el procedimiento de carga de las embarcaciones, así como por las chimeneas de la empresa; partículas que al final terminan en las aguas superficiales y sedimentos de la región.

En los últimos años la explotación masiva de los cerros aledaños, por parte de la propia empresa, para la obtención del material requerido para la fabricación de cemento, ha ocasionado daños ecológicos bastante graves, asociados a la utilización de dinamita. La deforestación de los cerros, así como la fragmentación de las rocas por las explosiones provoca un arrastre mayor de partículas hacia la zona costera, constituyéndose estas en una carga adicional para el ecosistema. 


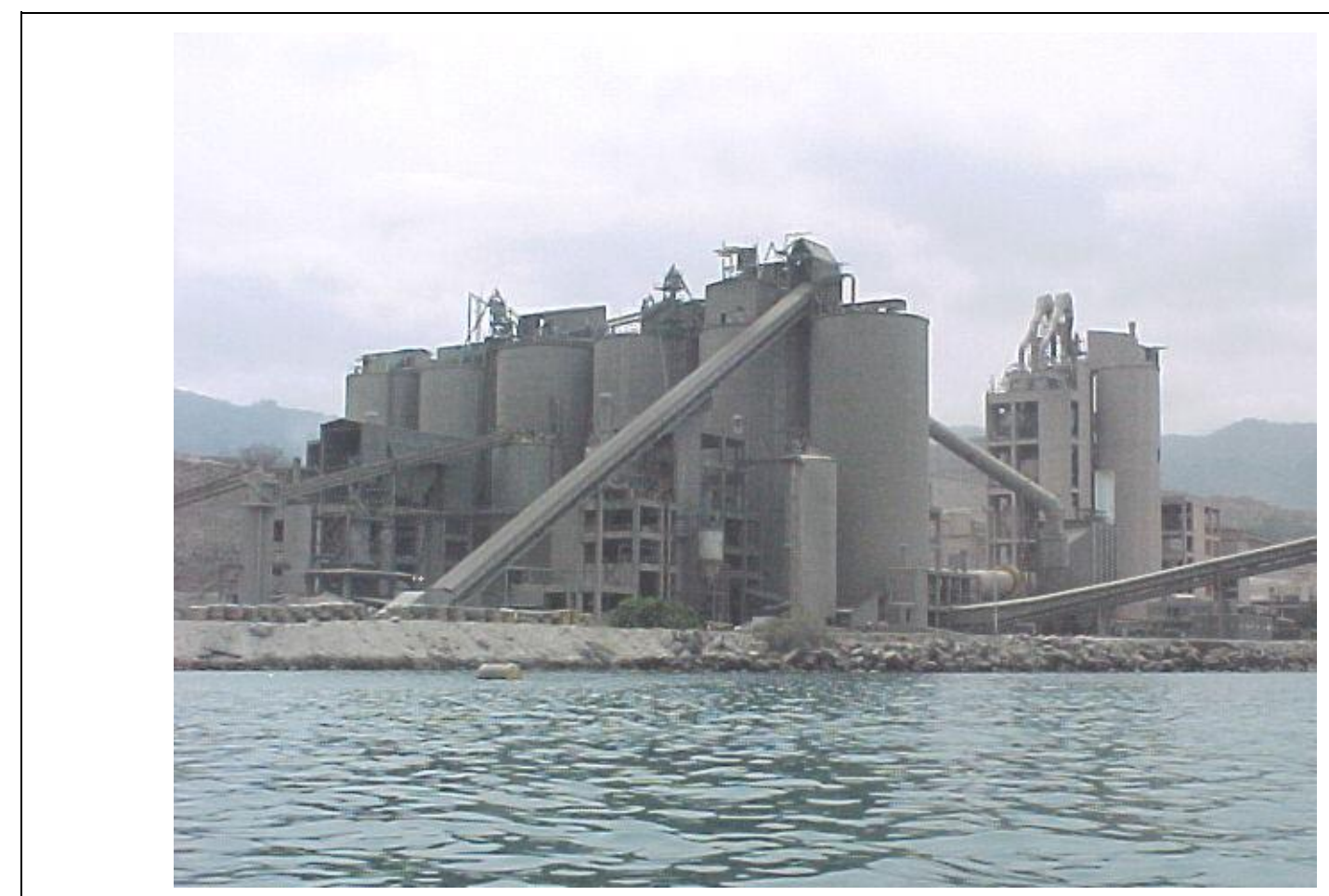

Foto 17.- Un acercamiento a la planta de producción de la empresa Vencemos. Bahía de Pertigalete.

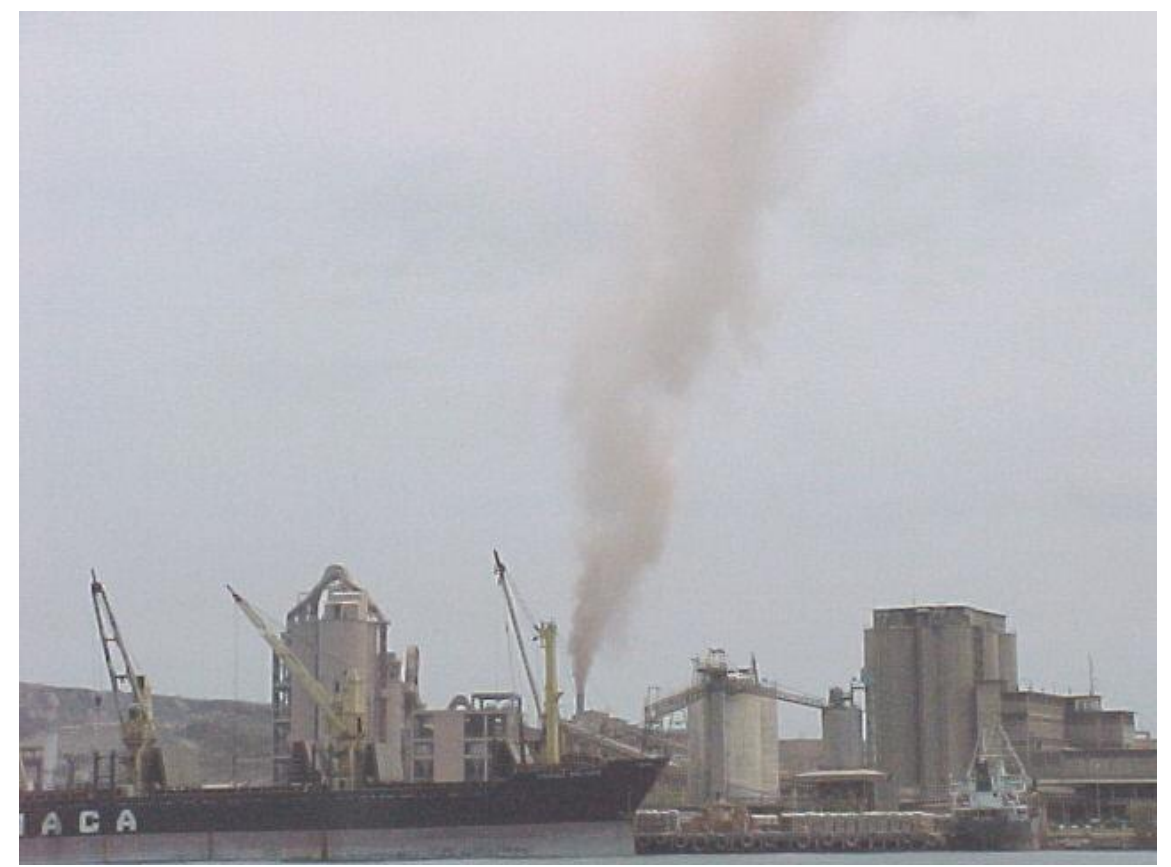

Foto 18.- Emisiones gaseosas provenientes de la planta de cementos Vencemos. Bahía de Pertigalete. 


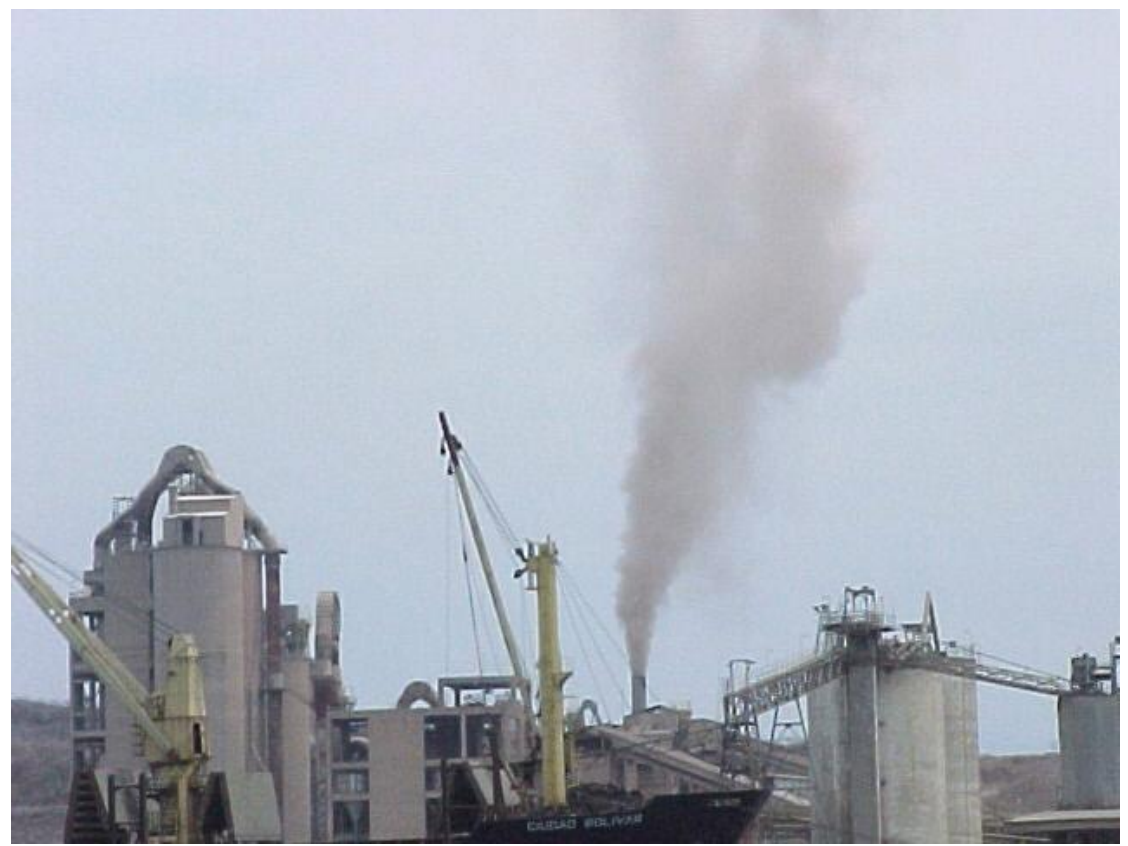

Foto 19.- Un acercamiento de la foto anterior.

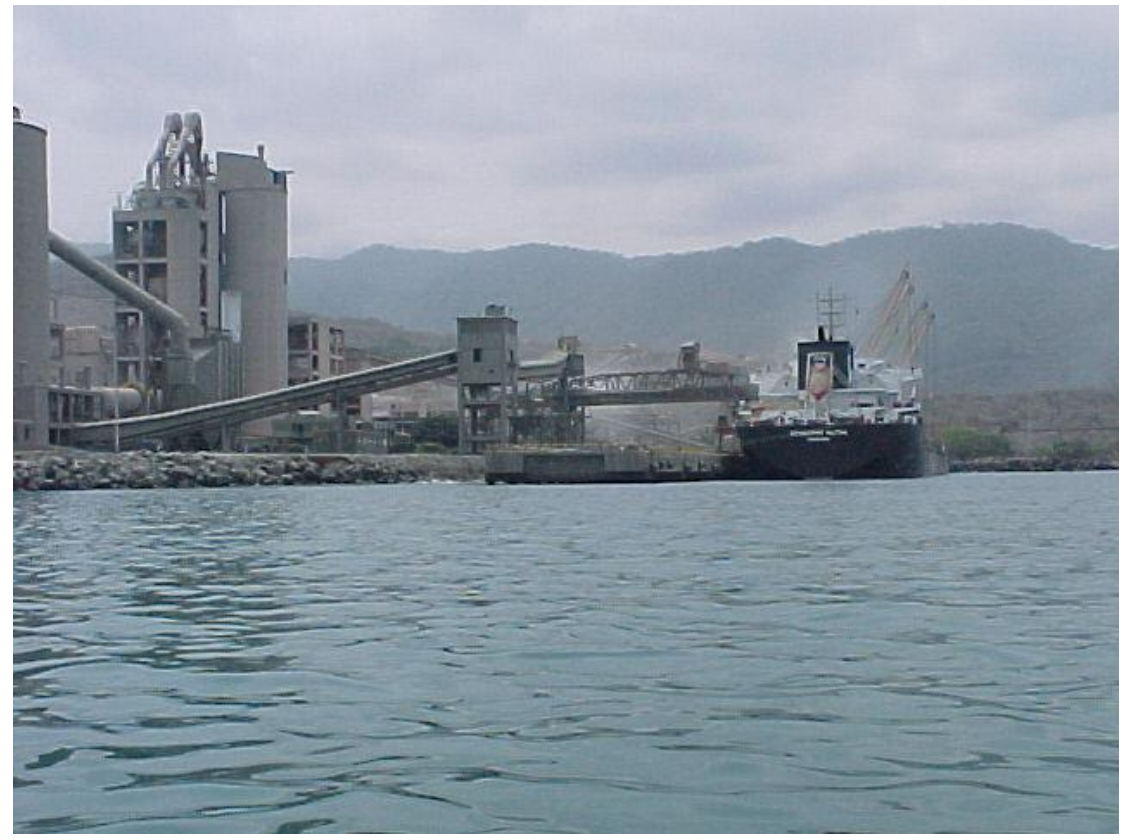

Foto 20 


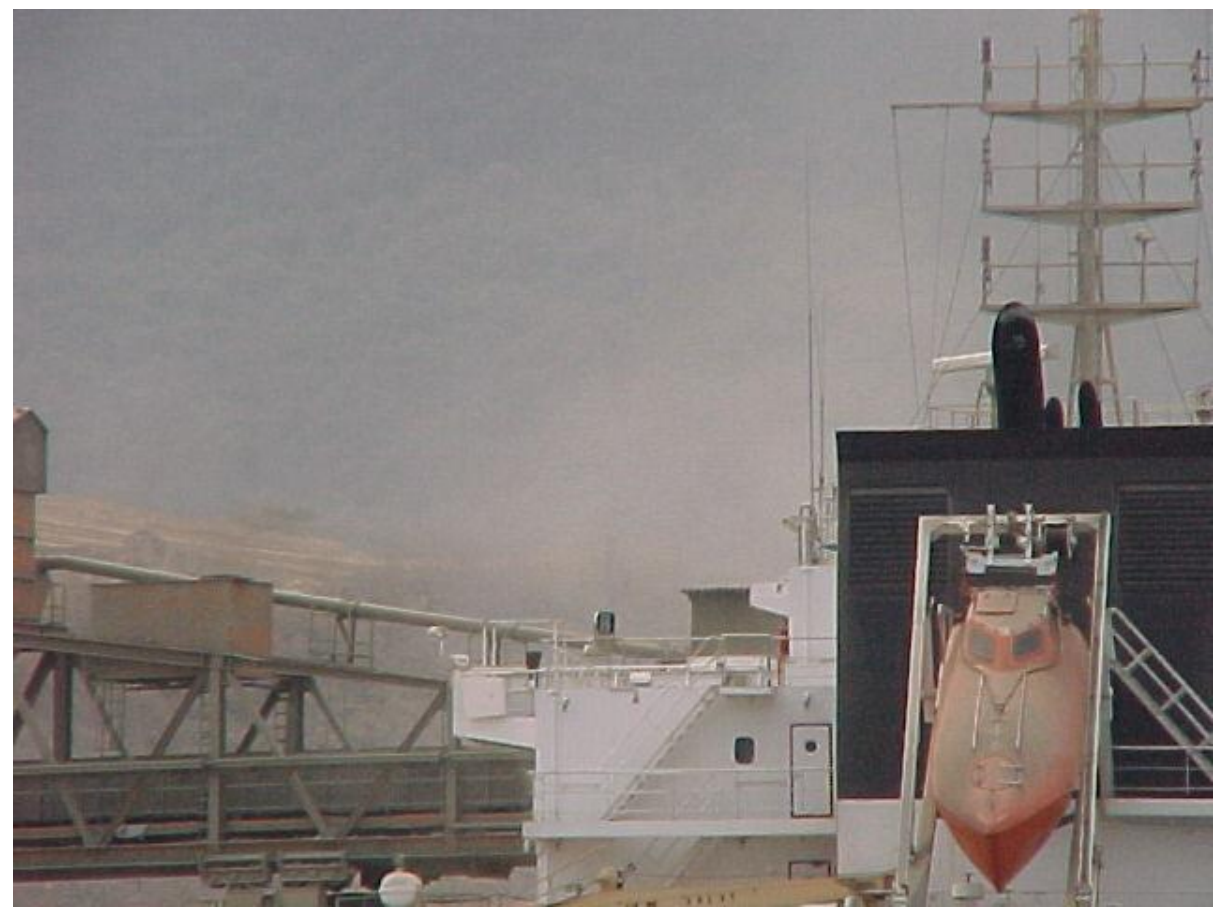

Foto 21

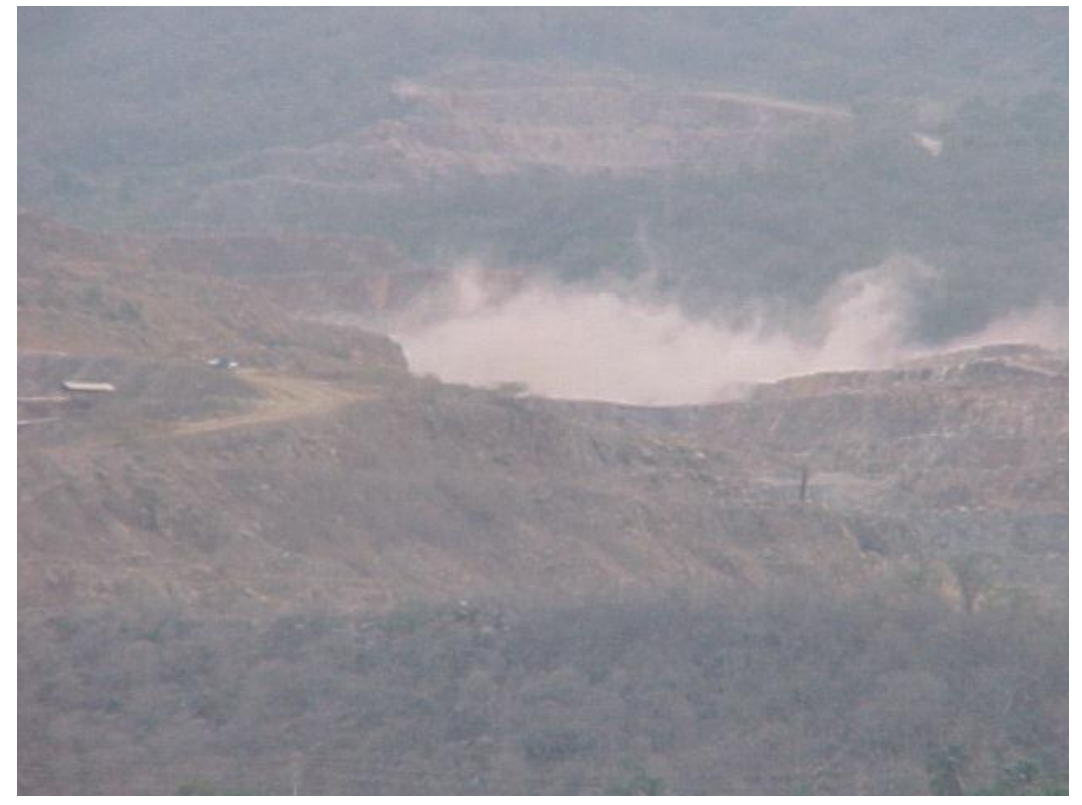

Foto 22

Hacia la región occidental de la bahía de Pertigalete se encuentra ubicada la población de Pamatacualito. Este sector presenta una gran actividad turística, ya que es utilizada por los visitantes 
como embarcadero para el traslado a las islas que se encuentran en la región, de manera particular Isla de Plata, gran centro turístico. El número de embarcaciones que se movilizan en la región es bastante elevado. En el mismo sector se encuentra ubicada la planta de la empresa Baroid, la cual vierte sus efluentes al ecosistema costero, coadyuvando al deterioro del mismo.

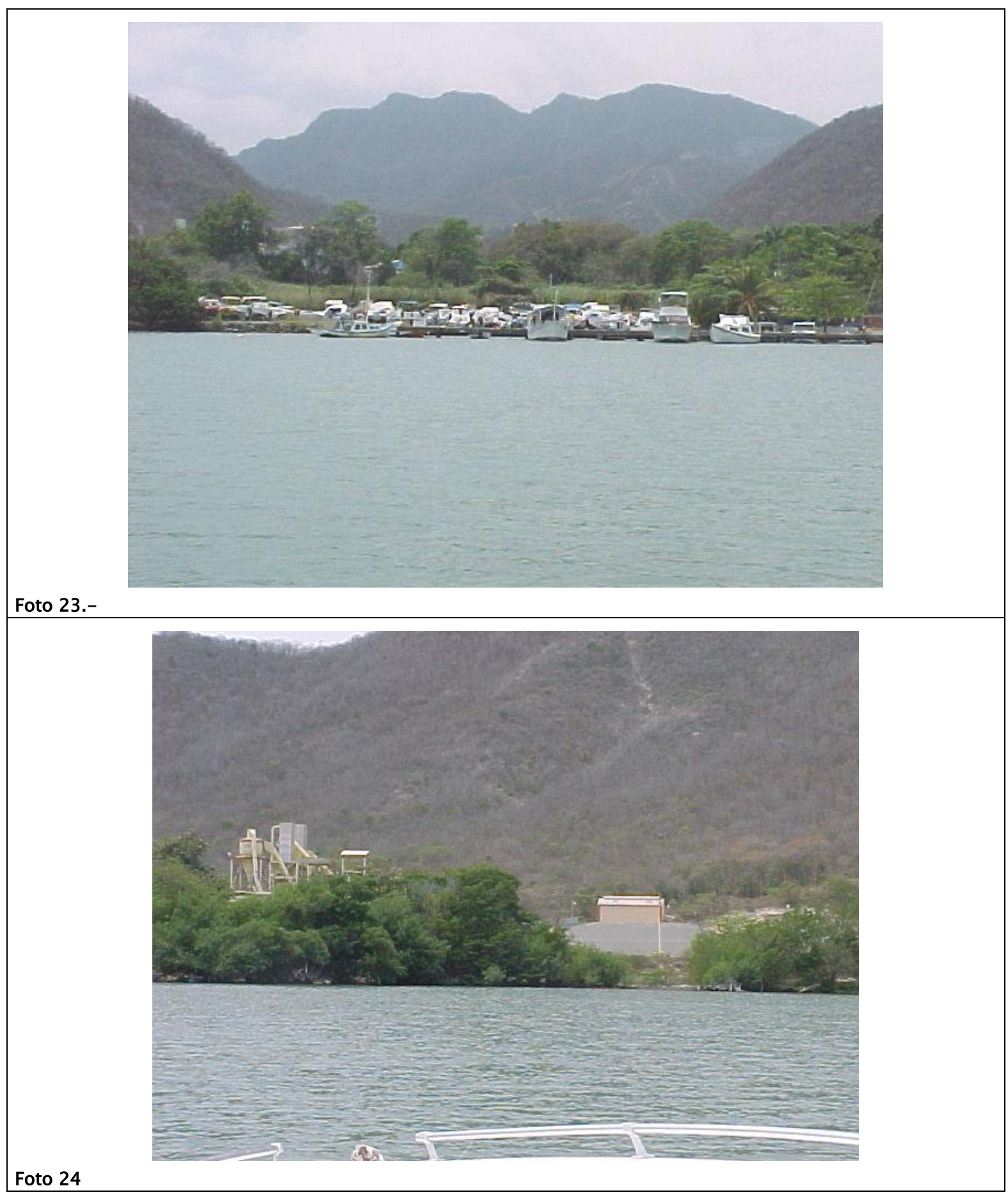

